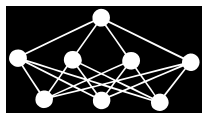

\title{
COMPUTATIONAL MODELING OF ELECTRICITY CONSUMPTION USING ECONOMETRIC VARIABLES BASED ON NEURAL NETWORK TRAINING ALGORITHMS
}

\author{
T.M. Usha, S. Appavu alias Balamurugan ${ }^{\dagger}$
}

\begin{abstract}
Recently, there has been a significant emphasis in the forecasting of the electricity demand due to the increase in the power consumption. Energy demand forecasting is a very important task in the electric power distribution system to enable appropriate planning for future power generation. Quantitative and qualitative methods have been utilized previously for the electricity demand forecasting. Due to the limitations in the availability of data, these methods fail to provide effective results. With the development of the advanced tools, these methods are replaced by efficient forecasting techniques. This paper presents the computational modeling of electricity consumption based on the Neural Network (NN) training algorithms. The main aim of the work is to determine the optimal training algorithm for electricity demand forecasting. From the experimental analysis, it is concluded that the Bayesian regularization training algorithm exhibits low relative error and high correlation coefficient than other training algorithms. Thus, the Bayesian Regularization training algorithm is selected as the optimal training algorithm for the effective prediction of the electricity demand. Finally, the economic input attributes are forecasted for next 15 years using time series forecasting. Using this forecasted economic attributes and with the optimal Bayesian Regularization training algorithm, the electricity demand for the next 15 years is predicted. The comparative analysis of the NN training algorithms for the proposed dataset and larger datasets obtained from the UCI repository and American Statistical Association shows that the Bayesian Regularization training algorithm yields higher correlation value and lower relative error than other training algorithms.
\end{abstract}

Key words: activation functions, neural network model, neural network training algorithms, Bayesian regularization training algorithm, time series forecasting, electricity demand forecasting

Received: February 24, 2015

DOI: $10.14311 / N N W .2017 .27 .007$

Revised and accepted: October 1, 2016

*T.M. Usha - Corresponding author; Information and Communication Engineering, Anna University, India, E-mail: ashariniharish@yahoo.co.in

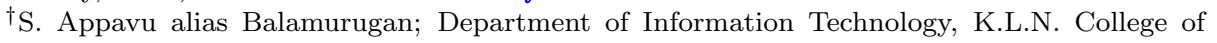
Information Technology, Tamil Nadu, India, E-mail: app_s@yahoo.com 


\section{Introduction}

Electricity demand forecasting [55] plays a vital role in the planning of the electricity production, since it determines the quantity of the required resources to operate the electricity plants. Further, it is the cornerstone of planning for electric plants and networks. Prediction of the electric load demand pattern is very complex, due to the irregular nature of the energy markets. It is therefore necessary to develop new prediction methods to reduce the uncertainty of the predictions. Accurate demand forecasting enables to make correct decisions for future planning and development. This enables significant reduction in the operation and maintenance costs and improved reliability of the power supply and distribution system. It is really a critical task to find an appropriate forecasting model for the electricity demand forecasting. Many forecasting methods are developed to solve this problem.

Traditional forecasting techniques such as time series, regression, econometric and soft computing techniques such as Fuzzy logic, genetic algorithm and NNs are utilized for the electricity demand forecasting [43]. But, none of these methods have been generalized for the demand patterns of the power distribution network. Among all the existing time series prediction models, the NN [4] shows better performance in terms of the relative error and correlation coefficient than any other model.

The NN model [5] is a recently developed class of nonlinear models, based on the principles derived from the structure of the brain. The NNs are trained by using the training algorithms. There are three types of training algorithms that are found to be effective for variable range of weights.

- The Newton algorithm is found to be efficient for a small number of weights. The memory requirement of this algorithm is directly proportional to the square of the number of weights.

- Various Quasi-Newton algorithms are efficient for a moderate number of weights. The memory requirement of these algorithms is directly proportional to the square of the number of weights.

- Various conjugate-gradient algorithms are efficient for a large number of weights. The memory requirement of these algorithms is directly proportional to the number of weights.

The main disadvantage of the existing prediction models is its difficulty with infinite recursion and structured representations. Hence, an efficient prediction model is required to overcome these shortcomings. The purpose of this work is to determine the optimal prediction method for forecasting electricity demand using an economic data set. The main focus is to find an optimal training algorithm for the forecasting purpose. All the prediction techniques are applied to the dataset compiled from the Tamil Nadu Electricity Board and Statistical Department.

The empirical comparison results show that the Bayesian Regularization training algorithm achieves significant reduction in the relative error and high correlation coefficient, among all other training algorithms. Based on this concept, the optimal training algorithm is determined based on the correlation coefficient 
and relative error of the training algorithms. Therefore, it is concluded that the Bayesian Regularization training algorithm is the optimal training algorithm for electricity demand forecasting.

The rest of the paper is systematized as follows: Section 2 describes the existing works related to the electricity demand forecasting techniques. Section 3 illustrates the NN model used in this work. Section 4 describes the activation functions for NN. Section 5 explains about the classification of the NN training algorithms. Section 6 presents the dataset description and Section 7 involves the results and discussion including the comparative analysis of the relative error and correlation coefficient of various training algorithms and ranking of the training algorithms. The conclusion and future implementation of this work are discussed in the Section 8.

\section{Literature survey}

This section explains about the existing electricity demand forecasting techniques. Various types of classifications based on the forecasting methods were introduced over a period of time. [55] developed an improved hybrid model including moving average, combined method, hybrid model and adaptive PSO algorithm (MA-C$\mathrm{WH}$ ) for forecasting electricity demand in China. The performance of the proposed MA-C-WH model was compared with the existing seasonal ARIMA (SARIMA). Based on the results of popular forecasting precision indexes, the proposed model was found to be effective for seasonal time series with nonlinear trend. [43] reviewed the various energy demand forecasting models including traditional methods and soft computing techniques. The support vector regression, optimization techniques such as Ant Colony Optimization (ACO) and Particle Swarm Optimization (PSO) were also adopted for energy demand forecasting. The Market Allocation (MARKAL) and Long range Energy Alternatives Planning (LEAP) models were also used for the energy demand management. [14] proposed a NN based approach for selecting the best prediction method depending on small number of customers. The proposed approach did not require frequent retraining.

[5] developed a weighted fuzzy NN for monthly electricity demand forecasting in Taiwan. The fuzzy NN framework was modified and the significance of every factor amongst the different rules was calculated using a weighted factor. The NN was trained using the historical data, to forecast the future electricity demands. The monthly electricity demand forecasting accuracy of the NN model was higher than the other approaches. [2] proposed a novel approach that combined multioutput feed forward NN with filtering and seasonal adjustment. Empirical mode decomposition (EMD) based signal filtering was performed for reducing the noise signals. The seasonal component was removed from the denoised series and the resultant series was modeled with a multi-output strategy. The season indexes were restored to the forecasts and final prediction was obtained. The forecasting accuracy was improved compared to the existing models.

[49] analyzed the PSO optimal Fourier Method, seasonal Autoregressive Integrated Moving Average Model (ARIMA) model and also combined models of both techniques for correcting the seasonal ARIMA forecasting results. The prediction accuracy of the three residual modification models was better than single seasonal 
ARIMA model. The combined model was found to be more satisfactory than the models. [45] introduced a decomposition approach for modeling the variation in the electricity demand trend for medium and long-term forecasting. The historical time series was decomposed into a number of components according to the seasonality variation, daily activity and day of the week. However, the decomposition approach was relatively feasible for implementation, since it did not require the structural models or time series analysis and reduced the complex non-linear parameter estimation efforts.

[32] proposed a hybrid forecasting framework including a Multi-Input MultiOutput (MIMO) forecasting engine to predict the electricity demand and price. A Data Association Mining (DAM)-based rule extraction mechanism was employed for determining and extracting the customer reaction patterns to the price forecast. These extracted rules were used for tuning the initial forecasts of the MIMO engine. [44] introduced a semi-functional partial linear model for forecasting the electricity demand and price. The new forecasting model was compared with a naïve method and seasonal ARIMA model. The performance of the new forecasting model was better for the electricity demand forecasting than the price forecast. [39] presented a new mid-term electricity demand forecasting framework for the practical and reliable forecast using the measurable amount of external variables. The performance result of the proposed approach was better than the decomposition forecasting methods. [47] proposed a novel approach that combined the first-order gray differential equation and seasonal fluctuation from time series method. The proposed model achieved a better performance than the original gray differential equation model.

A nonlinear time series modeling technique was applied to analyze the electricity demand. A weighted largest Lyapunov exponent forecasting method was proposed to improve the prediction accuracy. The PSO algorithm was used for determining the optimal weight parameters of the forecasting method. The mean absolute relative error (MARE) of the prediction model was relatively lower than the forecasting errors of the existing methods [46]. [18] discussed the most relevant studies on electricity demand prediction over the last 40 years, and presented different models for the future trends. Additionally, the latest studies on the demand forecasting were analyzed in the future environments [53] modeled the electricity demand in the Ontario province by using a neuro Fuzzy inference system. A neurofuzzy model was created for the electricity demand, based on the data collected using statistical methods [8] investigated the relationship between Turkish residential electricity consumption, using the application of the structural time series model to the annual data. Finally, the Turkish residential electricity demand was predicted accurately, based on different forecast assumptions.

[52] developed a hybrid energy demand forecasting procedure with higher precision, using PSO-Genetic Algorithm (GA) approach. The superior performance of the proposed forecast method was higher than the single optimization methods and multiple linear regressions. [19] presented a Multi-Agent System (MAS) model for virtual power plants. A set of agents was embedded with artificial NNs for the collaborative forecasting of disaggregated energy demand of the domestic users. The MAS was fed with relevant data to make informed decision, due to the reduction in the error rate. [25] proposed a new hybrid method including PSO and 
ACO for estimating energy demand of Turkey. Estimation of the future energy demand was done under different scenarios. The relative estimation errors of the HAPE model were low and fitting solutions were provided. [40] proposed a Pattern Forecasting Ensemble Model for day-ahead prediction of electricity demand. Five forecasting models were implemented using different clustering techniques based on the Pattern Sequence Similarity algorithm. The performance of the proposed model was evaluated on electricity demand datasets and compared with five forecasting models. The performance of the proposed model was better in terms of Mean Relative Error (MRE) and Mean Absolute Error (MAE), when compared to the five forecasting models.

[41] presented a regression-SARIMA model with generalized autoregressive conditional heteroskedastic (GARCH) for the electricity demand forecasting. Due to the non-constant mean value and variance of the daily peak demand data and multiple seasonality variation corresponding to weekly and monthly data, the possibility of serial correlation in the instability was solved using the GARCH modeling methodology. The forecasting accuracy of the proposed model was improved, while enabling reduction in the mean absolute percent error. [9] investigated the relationship between the variables such as Gross Domestic Product, aggregate electricity consumption rate and price to forecast the future aggregate electricity demand in Turkey. The structural time series technique was applied to the annual data over a certain time period to estimate aggregate electricity demand function for Turkey. Efficient prediction of aggregate electricity demand was performed based on the estimated equation.

\section{NN model}

The model that predicts the relationship between the input and output values with the sufficient learning repetitions is called Neural network (NN) models. The approximation of non-linear decision boundaries required the high precision with less computational time. The non-linear functions are utilized to compute the most fitting during the transformation of input variables. The NN model includes the input layer, hidden layers and an output layer with summation and activation function. The correlation estimation calculates the linear relationship between the input and output variables. The number of neurons in the hidden layers is responsible for relationship measurement. The NN model comprises of an input layer, few hidden layers, and an output layer. Fig. 1 shows the single neuron. A feedforward artifician NN model includes a summation function and activation function ' $\mathbf{G}$ ' as shown in Fig. 2. This network is made up of many nodes connected parallelly and in series.

$$
\begin{gathered}
n_{i}=\sum_{j=1}^{k} w_{j i} x_{j}+\theta_{i}, \\
y_{i}=\mathbf{G}_{i}=\mathbf{G}\left(\sum_{j=1}^{k} w_{j i} x_{j}+\theta_{i}\right),
\end{gathered}
$$




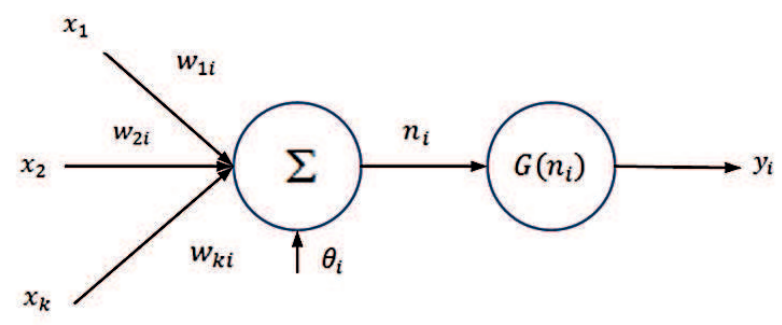

Fig. 1 Single Neuron.

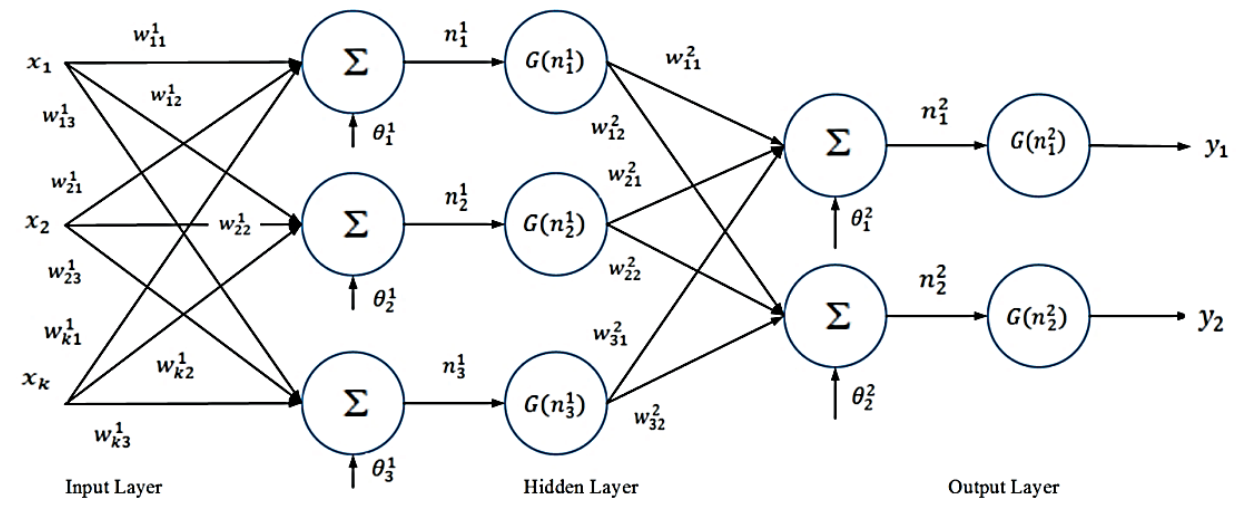

Fig. 2 Feedforward NN model.

$$
y_{i}=g\left(\sum_{j=1}^{3} w_{j i}^{2} g\left(n_{j}^{1}\right)+\theta_{j}^{2}\right)=g\left(\sum_{j=1}^{3} w_{j i}^{2} g\left(\sum_{k=1}^{k} w_{k j}^{1}+\theta_{j}^{1}\right)+\theta_{j}^{2}\right) \text {, }
$$

where



The architecture 9-6-5-1 has the highest correlation value as shown in Fig. 3. So, this architecture is chosen for the NN training. The architecture has 9 neurons in the input layer, 6 neurons in the first hidden layer, 5 neurons in the second hidden layer, and 1 neuron in the output layer. 


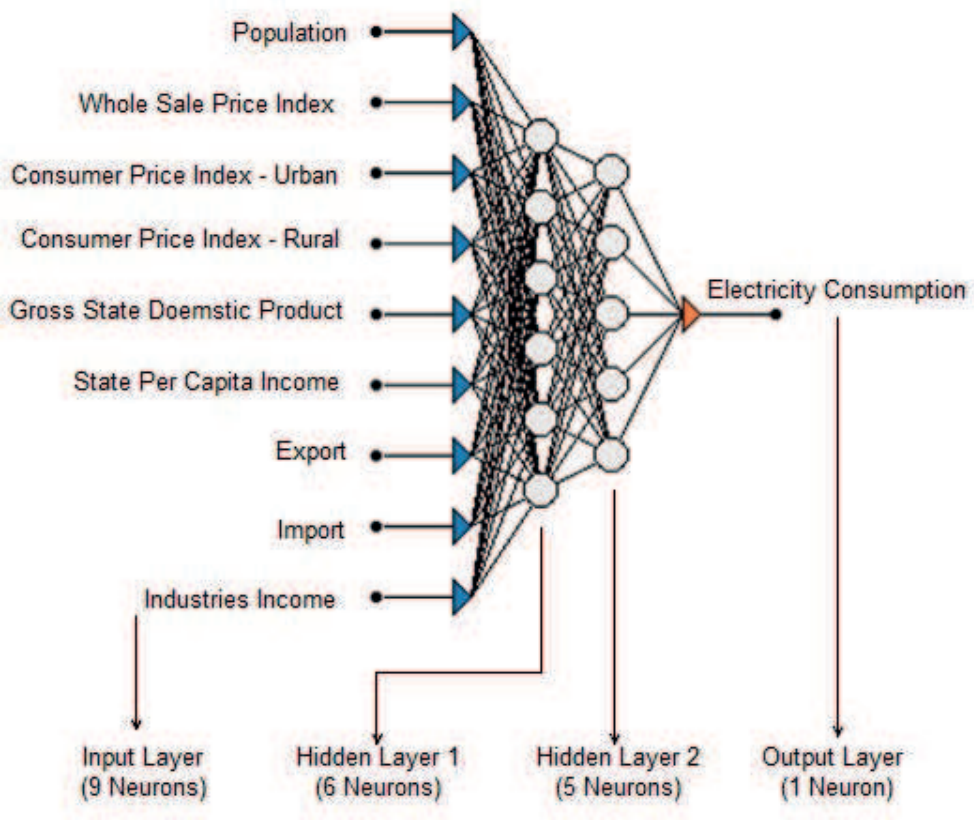

Fig. 3 Optimal Architecture 9-6-5-1.

\subsection{NN parameters}

NN parameters are used to obtain maximum similarity between the input and output values. So, the error between the desired and actual outputs is reduced. These NN parameters are very important and sensitive to the accuracy of the prediction. Therefore, setting the NN parameters is very significant. While creating a NN, selection of the input variable is mainly important to obtain a meaningful prediction. The variables that influence the target variable are selected as input variable. The correlation value is calculated between the input and target variables to measure their linear relationships. The numbers of hidden layers and the numbers of neurons in the hidden layers are also important for the NN architecture. These values are obtained by continuously changing the configuration during the training process using a number of ancillary algorithms. The correlation value is calculated for different combinations of numbers of hidden layers and numbers of neurons. The NN is trained with a learning algorithm called a training algorithm. Here, the $\mathrm{NN}$ is evaluated using different training algorithms including back propagation algorithms, gradient descent methods, conjugate gradient descent, variable metric methods and regularization methods. An activation function specifies the output of a neuron for a given input. Neurons are 'switches' that outputs ' 1 ' when they are sufficiently activated and ' 0 ' when not activated.

Training algorithms are the optimization procedures used for automatic adjustment of the weights and biases of the network. The main objective of the training algorithms is to reduce the global error $\mathbf{G}_{\mathrm{E}}$ defined as 


$$
\mathbf{G}_{\mathrm{E}}=\frac{1}{\mathrm{tp}} \sum_{\mathrm{tp}=1}^{\mathrm{tp}} E_{\mathrm{tp}}
$$

where tp is the total amount of training patterns and $E_{\mathrm{tp}}$ is the error contained in the training pattern. $E_{\mathrm{tp}}$ is calculated as

$$
E_{\mathrm{tp}}=\frac{1}{2} \sum_{i=1}^{N}\left(o_{i}-t_{i}\right)^{2},
$$

where $N$ is the total number of the output nodes, $o_{i}$ denotes the output of the network at the $i$-th output node, and $t_{i}$ is the target output at the $i$-th output node. This global error is reduced by adjusting the weights and biases.

\section{Activation functions for NN}

The NN $[6,20,35]$ is used in the time series prediction to find the best relationship between the input and output values for a sufficient number of learning repetitions. Here the dataset is partitioned into two sets of data for training and testing. They allow the complex nonlinear relationships between the response variable and its predictors. The NN models [17] have concentrated on forecasting future developments of the time series from values of $x$ up to the current time. The advantage of the NN includes automatic learning of dependencies only from measured data without the need to add further information.

\subsection{Hyperbolic tangent function}

The hyperbolic tangent function [42] is the most common activation function for the NNs, which produces output values ranging from -1 to 1 . It is defined as the ratio between the hyperbolic sine and cosine functions or the ratio of the difference and sum of two exponential functions as seen below

$$
\tanh (x)=\frac{\sinh (x)}{\cosh (x)}=\frac{\mathrm{e}^{x}-\mathrm{e}^{-x}}{\mathrm{e}^{x}+\mathrm{e}^{-x}} .
$$

The sigmoid activation function does not return the values less than zero. But, it is possible to move the sigmoid function towards a region with negative values. This is performed by using the hyperbolic tangent function. Because of this higher numeric range, the hyperbolic activation function is often used instead of the sigmoid activation function. The tangent hyperbolic function is a bipolar version of the sigmoid function. Fig. 4 shows the hyperbolic tangent function.

\subsection{Linear activation function}

Another common activation function for the NNs is the linear activation function [27]. This function only produces positive numbers over the whole range of real numbers. The mathematical formula for this function is shown as

$$
f(x)=x \text {. }
$$




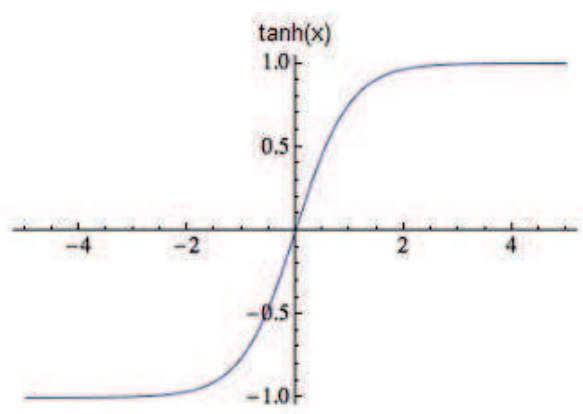

Fig. 4 Hyperbolic tangent function.

\subsection{Uni-Polar sigmoid function}

The sigmoid function produces the positive output values ranging from 0 to 1 . Activation function of the uni-polar sigmoid function [33] is defined as

$$
F(x)=\frac{1}{\left(1+\mathrm{e}^{-x}\right)} .
$$

This function is especially advantageous for NNs trained by back-propagation algorithms. As it is easy to distinguish, it minimizes the computation capacity for training. Since the sigmoid activation function includes single constant derivative, it is suitable only for the output layer of the $\mathrm{NN}$ trained with the gradient descent based training methods. Fig. 5 shows the uni-polar sigmoid function.

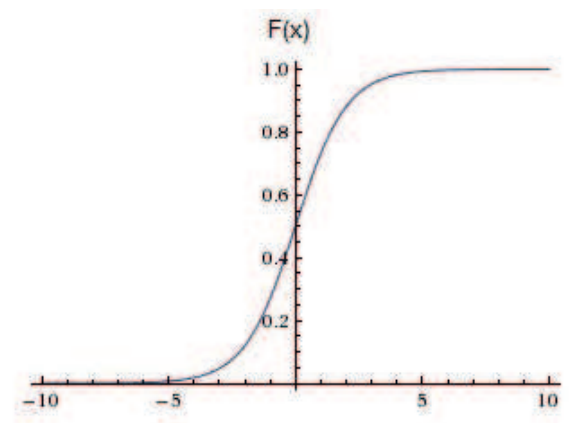

Fig. 5 Uni-Polar Sigmoid Function.

\subsection{Bi-Polar sigmoid function}

The bi-polar sigmoid function produces the output values in the range of $[-1,1]$. Fig. 6 shows the bi-polar sigmoid function. Activation function of the Bi-polar sigmoid function [11] is given by

$$
F(x)=\frac{1-\mathrm{e}^{-x}}{1+\mathrm{e}^{-x}} .
$$




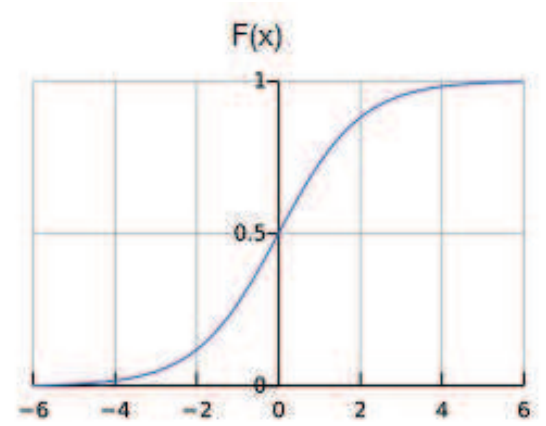

Fig. 6 Bi-polar sigmoid function.

\section{Classification of $\mathrm{NN}$ training algorithms}

Tab. I shows the training algorithms used for training the NN. With the optimal NN architecture, 17 different training algorithms and 9 sets of different combinations of 3 activation functions for the hidden layer and output layer are used in the NN training. This NN predicts the electricity consumption. The main function, advantages and drawbacks of the training algorithms are discussed in this section.

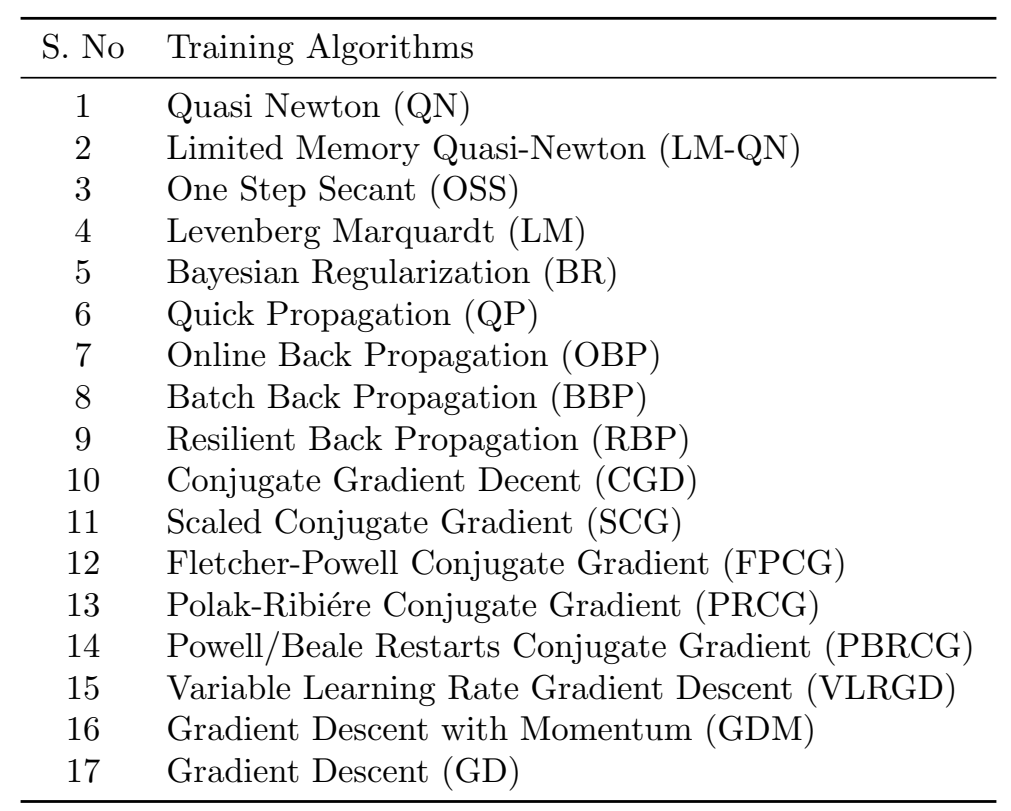

Tab. I Neural Network training algorithms. 


\subsection{Bayesian regularization}

Bayesian regularization $[31,50]$ is a mathematical process that converts a nonlinear regression into a well-modeled statistical problem in the manner of a ridge regression. It is the most suitable method for the estimation when a large number of inputs is used for the best output. Bayesian regularization reduces the linear combination of the squared errors and weights. It also adjusts the linear combination to produce the network with good generalization qualities at the end of training. The Bayesian optimization of the regularization parameters requires the computation of the Hessian matrix of $\boldsymbol{F}(\mathbf{w})$ at the minimum point $\mathbf{w}^{*} . \boldsymbol{F}$ is the objective function and $\mathbf{w}$ is the vector of network parameters.

The Bayesian regularization requires numerical approximation of analytically intractable integrals. It provides the estimated values based on the prior approximations of the parameters. These approximations are expressed with the probability density functions. In this technique, the number of subjective choices specifications is required for the prior parameters. The prior confidence about the parameters is approximated before collecting the data. It is also used to estimate the parameters of unknown model by combining the prior knowledge and the observed data for providing a probability distribution. The regularization parameters $\alpha$ and $\beta$ are calculated as follows:

$$
\begin{gathered}
\alpha=\frac{\rho}{2 E_{\mathrm{w}}}, \\
\beta=\frac{E_{\mathrm{D}}-\rho}{2 E_{\mathrm{D}}},
\end{gathered}
$$

where, $\alpha$ and $\beta$ are the objective functions, $\rho$ defines the effective number of parameters, $E_{\mathrm{w}}$ is the error of weights and $E_{\mathrm{D}}$ is the error of data points. It treats the weight values as a random variables and assumes that the prior probabilities of $P$ are Gaussian. The following mathematical model is used to compute the regularization

$$
P(\mathbf{v} \mid S, \alpha, \beta, N)=\frac{P(S \mid \mathbf{v}, \beta, N) P(\mathbf{v} \mid \alpha, N)}{P(S \mid \alpha, \beta, N)},
$$

where $S$ denotes the dataset, $N$ represents the particular NN model, $\mathbf{v}$ is the vector of network weights, $P(S \mid \mathbf{v}, \beta, N)$ defines the likelihood function that is the probability of the occurring data for the weights $\mathbf{v}, P(\mathbf{v} \mid \alpha, N)$ represents the prior density of the weights and $P(S \mid \mathbf{v}, \beta, N)$ is the normalization factor that guarantees the probability as 1 .

\subsection{Levenberg-Marquardt}

The Levenberg-Marquardt (LM) algorithm [7,13] is one of the most popular tools for solving the non-linear minimum mean squares problems. This algorithm is designed to attain the second-order training speed, without the need for computing the Hessian matrix. The Hessian matrix can be approximated as

$$
\mathbf{H}=\mathbf{J}^{\mathrm{T}} \mathbf{J}
$$


The gradient is computed as

$$
\mathbf{G}=\mathbf{J}^{\mathrm{T}} \mathbf{e}
$$

where $\mathbf{e}$ is a vector of network errors and $\mathbf{J}$ is the Jacobian matrix containing first derivatives of the network errors corresponding to the weights and biases. The Jacobian matrix is calculated using a standard back-propagation technique, which is really simpler than the Hessian Matrix computation.

\subsection{Scaled Conjugate Gradient}

The Scaled Conjugate Gradient (SCG) descent algorithm [22, 24, 38, 51] does not require the computationally expensive line search and at the same time possess the advantage of the Conjugate Gradient descent algorithms. The step size in the conjugate direction in this case is determined using the LM approach. The algorithm starts in the direction of the steepest descent given by the negative of the gradient as

$$
P_{u}=-\nabla V_{u},
$$

where $P_{u}$ is the search direction, $\nabla$ is the gradient and $V_{u}$ is the direction.

The updated weights and biases are then given by

$$
X_{k+1}=X_{k}-\alpha_{k} P_{k},
$$

where $X_{k}$ is the weights, $\alpha_{k}$ is the step size determined by the Levenberg-Marquardt algorithm.

The next search direction that is conjugate to the previous search directions is determined by the combination of the previous search direction with the new steepest descent direction. This is given by

$$
P_{k}=-\nabla V_{k}+\beta_{k} P_{k-1},
$$

where $\beta_{k}$ is defined as

$$
\beta_{k}=\frac{\left|\nabla v_{k+1}\right|^{2}-\nabla V_{k+1} \nabla V_{k}}{\mu_{k}},
$$

and where $\mu_{k}$ is given by

$$
\mu_{k}=P_{k}^{T} \nabla V_{k}
$$

\subsection{Back propagation}

The back propagation algorithms $[48,51]$ performs the training of a feed-forward multilayer NN for a given set of input patterns with known classifications. The network examines its output response to the sample input pattern, during the presentation of every entry of the sample set to the network. The output response is then compared with the known and desired output and the error value is calculated. The connection weights are adjusted based on the error value. 


\subsection{Resilient back propagation}

The main purpose of the resilient back propagation $[28,37]$ is to eliminate the detrimental effects of the degree of the partial derivatives. The direction of the weight update is determined only by the sign of the partial derivative. The magnitude of the partial derivative does not have any effect on the weight update. By using a different update value, the size of the weight change is determined.

There is an increase in the update value for every weight and bias by a specific factor, when the derivative of the performance function holds the same sign for two successive iterations, with respect to that particular weight. The update value is reduced by the factor, when the derivative changes sign from the previous iteration, with respect to that weight. The update value for the weight and bias remains the same, if the derivative is zero. The weight change is decreased, during variations in the weights. The magnitude of the weight change increases, if the weight change continues in the same direction for multiple iterations.

$$
\begin{gathered}
\Delta W_{i j}(t)= \begin{cases}-\Delta P_{i j}, & \text { if } \frac{\partial E}{\partial W_{i j}}(t)>0 \\
-\Delta P_{i j}, & \text { if } \frac{\partial E}{\partial W_{i j}}(t)<0 \\
0, & \text { if } \frac{\partial E}{\partial W_{i j}}(t)=0\end{cases} \\
\Delta P_{i j}(t)= \begin{cases}\alpha^{+} \cdot \Delta W_{i j}(t-1), & \text { if } \frac{\partial E}{\partial W_{i j}}(t-1) \cdot \frac{\partial E}{\partial W_{i j}}(t)>0 \\
\alpha^{-} \cdot \Delta W_{i j}(t-1), & \text { if } \frac{\partial E}{\partial W_{i j}}(t-1) \cdot \frac{\partial E}{\partial W_{i j}}(t)<0, \\
\Delta W_{i j}(t-1), & \text { if } \frac{\partial E}{\partial W_{i j}}(t-1) \cdot \frac{\partial E}{\partial W_{i j}}(t)=0\end{cases}
\end{gathered}
$$

where $\alpha$ is the learning rate, $W$ is the weight, $P$ is the change in the weight, $\alpha^{+}=1.2$ and $\alpha^{-}=0.5$.

\subsection{Online back propagation}

The online back propagation algorithm is a heuristic method that includes two phases. During the first phase, the learning rate is adjusted after every iteration, so as to quickly attain the minimum value of the error criteria on the validation set. The search process is refined during the second phase, by repeatedly returning to previous weight configurations and reducing the global learning rate. Training is performed online, i.e. the weights of the $\mathrm{NN}$ are updated after the presentation of each training sample. The given weight $W_{i j}(t)$ is updated by adding a $\Delta W_{i j}(t)$ at every iteration $t$,

$$
\Delta W_{i j}(t)=-\varepsilon(t) \frac{\partial E(t)}{\partial W_{i j}(t)},
$$

where $\varepsilon$ is the learning rate. The validation set is used to control the adjustment of the learning rate $\varepsilon(t)$ after each training iteration $t$. The true gradient descent is not involved in this method, since the sum of all pattern derivatives over the given iteration is never determined for a particular set of weights. Instead of 
this, the weights are changed slightly after each pattern, by evaluating the pattern derivatives that are relative to slightly different weight values.

\subsection{Batch back propagation}

In the batch back propagation approach [54], all patterns are provided for the network before the learning process. In the batch training protocol, initially all the training patterns are presented and their corresponding weight updates are summed. Then the actual weights in the network are updated. This process is repeated, until some stopping criterion is satisfied. In batch back propagation, there is no need to select the patterns randomly, since the weights are updated only after the presentation of all patterns.

In batch mode, the value of $\partial E_{P} / \partial W_{i j}$ is calculated after the submission of every pattern to the network. Then, the total derivative $\partial E / \partial W_{i j}$ is calculated during the end of a given iteration, by the summation of the individual pattern derivatives. The weights are updated, after the calculation of the total derivative. The batch mode approximates the gradient descent, as far as the learning rate $\varepsilon$ is smallest.

\subsection{Powell/Beale restarts conjugate gradient}

The Beale-Powell restart algorithm [38,51] is highly useful for the large-scale unconstrained optimization applications. The search direction is reset periodically accoding to the negative values of the gradient, based on the inequality condition. If the number of iterations becomes equal to the number of the network parameters such as weights and biases, there will be the occurrence of the standard reset point. The training efficiency is improved by other reset methods. Powell and Beale have proposed a reset method, if the orthogonality between the current gradient $\mathbf{g}_{k}$ and previous gradient $\mathbf{g}_{k-1}$ is low. This is validated using the following inequality:

$$
\left|\mathbf{g}_{k-1}^{\mathrm{T}} \mathbf{g}_{k}\right| \geq 0.2\left\|\mathbf{G}_{k}\right\|^{2} \text {. }
$$

The search direction is reset according to the negative value of the gradient, if this inequality condition is satisfied.

\subsection{Polak-Ribiere conjugate gradient}

Polak and Ribiere $[38,51]$ have proposed another version of the conjugate gradient algorithm. The search direction for each iteration is determined by

$$
P_{k}=-\mathbf{G}_{k}+\beta_{k} P_{k-1}
$$

where $P_{k}$ is a search direction.

For the Polak-Ribiére update, the constant $\beta_{k}$ is computed by

$$
\beta_{k}=\frac{\Delta g_{k-1}^{\mathrm{T}} \mathbf{G}_{k}}{g_{k-1}^{\mathrm{T}} \mathbf{G}_{k-1}} .
$$

This is defined as the ratio of the product of the previous gradient with the current gradient to the norm squared value of the previous gradient. 


\subsection{One-step secant}

As the Quasi-Newton algorithm exhibits high storage and computational complexity in each iteration when compared to the conjugate gradient algorithms, there arises a need for the secant approximation. The OSS training algorithm [51] needs minimum stotrage and computation requirements than the Quasi-Newton algorithm, and slightly high storage and computation requirements than the conjugate gradient algorithms. Thus, the OSS method is considered as a mutual compromise between the Quasi-Newton algorithms and conjugate gradient algorithms.

\subsection{Limited memory Quasi-Newton}

The Limited Memory Quasi-Newton method [12,36] is used to update the variables with indices outside the active set. The main idea behind this approach is to use the information from only the most recent iterations only, while the information from earlier iterations is discarded for reducing the memory consumption.

\subsection{Quasi-Newton}

Newton's method [4], is found to be an alternative for the conjugate gradient approaches because of its rapid optimization. The fundamental step of the Newton's method is

$$
X_{k+1}=X_{k}-\mathbf{A}_{k}^{-1} \mathbf{G}_{k},
$$

where $\mathbf{A}$ is the Hessian matrix of the performance index of the present values of the weights and biases.

Quasi-Newton method [10,24] involves a generation of a sequence of matrices $\mathbf{G}$ that represents increasingly accurate approximations to the inverse Hessian. Using only the first derivative information of $E$, the updated expression is presented as follows:

$$
\mathbf{G}_{k+1}=\mathbf{G}_{k}+\frac{\mathbf{P} \mathbf{P}^{\mathrm{T}}}{\mathbf{P}^{\mathrm{T}} \mathbf{V}}-\frac{\left(\mathbf{G}_{k} \mathbf{V}\right) \mathbf{V}^{\mathrm{T}} \mathbf{G}_{k}}{\mathbf{V}^{\mathrm{T}} \mathbf{G}_{k} \mathbf{V}}\left(\mathbf{V}^{\mathrm{T}} \mathbf{G}_{k} \mathbf{V}\right) \mathbf{U}^{\mathrm{T}}
$$

where $\mathbf{G}_{k}$ is a symmetric positive definite matrix and $\mathrm{T}$ represents the transpose of the matrix.

\subsection{Variable learning rate gradient descent}

The learning rate parameter is used to determine the fast convergence of the Backlinear Propagation (BP) to the minimum solution. The convergence is faster, when the learning rate is large and the step is big. To speed up the convergence time, the variable learning rate gradient descent $\mathrm{BP}$ utilizes larger learning rate $\alpha$, when the NN model is far from the solution and smaller learning rate $\alpha$, especially when the neural net is near the solution. The new weight vector $\mathbf{w}_{k+1}$ is adjusted $t$ the same as that is in the gradient descent with momentum above but with a varying $\alpha_{1}$. Typically, the new weight vector $\mathbf{w}_{k+1}$ is defined as

$$
\begin{gathered}
\mathbf{w}_{k+1}=\mathbf{w}_{k}-\alpha_{k+} 1 \mathbf{G}_{k}+\mu \mathbf{w}_{k-1}, \\
\alpha_{k+1}=\beta_{\alpha k},
\end{gathered}
$$


where

$$
\beta=\left\{\begin{array}{cc}
0.7 & \text { If new error }>1.04 \text { (old error) } \\
1.05 & \text { If new error }<1.04 \text { (old error) }
\end{array}\right.
$$

\subsection{Conjugate gradient descent}

In the conjugate gradient descent algorithms $[24,26]$ the search process is performed along the conjugate directions, to determine the step size. This produces generally faster convergence than the steepest descent directions. During every iteration, the step size is adjusted. The search direction during every iteration is determined by updating the weight vector as

$$
\mathbf{w}_{k+1}=\mathbf{w}_{k}+\alpha P_{k},
$$

where

$$
\begin{gathered}
P_{k}=-\mathbf{G}_{k}+\beta_{k} P_{k-1}, \\
\beta_{k}=\frac{\Delta \mathbf{G}_{k-1}^{\mathrm{T}} \mathbf{G}_{k}}{\mathbf{G}_{k-1}^{\mathrm{T}} \mathbf{G}_{k-1}}, \\
\Delta \mathbf{G}_{k-1}^{\mathrm{T}}=\mathbf{G}_{k}^{\mathrm{T}} \mathbf{G}_{k-1}^{\mathrm{T}} .
\end{gathered}
$$

\subsection{Quick propagation}

The Quick propagation algorithm [23] computes the weight change by using the quadratic function $f(x)=x^{2}$. Relating the secant to the quadratic function, it is possible to calculate the minimum point $f^{\prime}(x)=0$. The $X$-coordinate of the minimum point is decided as the new weight value.

$$
\begin{gathered}
S(t)=\frac{\partial E}{\partial W_{i}(t)}=\frac{\Delta w_{i}(t)}{\alpha}, \\
\Delta W_{i}(t)=\frac{S(t)}{S(t-1)-S(t)} \cdot \Delta W_{i}(t-1),
\end{gathered}
$$

where $W$ is the weight, $i$ is the neuron, $E$ is the error function, $t$ is the time and $\alpha$ is the learning rate.

\subsection{Gradient descent with momentum}

Momentum allows the network to respond to the local gradient, and also to the recent trends in the error surface. This also allows the network to ignore the small features in the error surface. The momentum constant is denoted as $\mu$ which exists between 0 to 1 range. When the momentum constant is 0 , the weight change is performed based only on the gradient. When the momentum constant is 1 , the new weight change is set to equal the previous weight change, while simply ignoring the gradient $[24,34]$. The new weight vector $\mathbf{w}_{k+1}$ is adjusted as

$$
\mathbf{w}_{k+1}=\mathbf{w}_{k}-\alpha \mathbf{G}_{k}+\mu \mathbf{w}_{k-1} .
$$


Usha T.M., Appavu alias Balamurugan S.: Computational modeling of electricity...

\subsection{Gradient descent}

The gradient descent algorithm [5, 22, 24] updates the weights and biases along the steepest descent direction. The network weights and biases are modified in a direction that reduces the performance function rapidly i.e. the negative of the gradient of the performance function. The updated weights and biases in this algorithm are given by

$$
\mathbf{x}_{k+1}=\mathbf{x}_{k}-\alpha_{k} \nabla \mathbf{G}_{k},
$$

where $\mathbf{x}_{k}$ is the vector of the current weights and biases, $\alpha_{k}$ is the learning rate and $\nabla \mathbf{G}_{k}$ is the current gradient of the performance function. Tab II shows the advantages and disadvantages of the NN training algorithms.

\begin{tabular}{|c|c|c|c|}
\hline S.No & $\begin{array}{c}\text { Training } \\
\text { algorithms }\end{array}$ & advantages & disadvantages \\
\hline 1. & 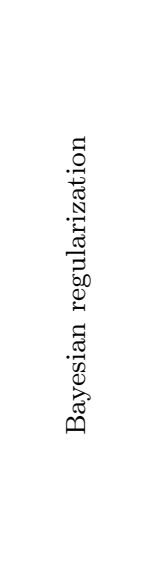 & $\begin{array}{l}\text { - Bayesian regularization ex- } \\
\text { pands the cost function to } \\
\text { search not only for the mini- } \\
\text { mal error, but also for the min- } \\
\text { imal error by using the mini- } \\
\text { mal weights. } \\
\text { - By using Bayesian regulariza- } \\
\text { tion, the need for a costly cross } \\
\text { validation is avoided. } \\
\text { - This also reduces the need for } \\
\text { testing the various numbers of } \\
\text { hidden neurons for a problem. } \\
\text {-Bayesian regularization pro- } \\
\text { vides better generalization per- } \\
\text { formance than others, since it } \\
\text { does not require a separate val- } \\
\text { idation dataset. }\end{array}$ & $\begin{array}{l}\text { - The main disadvantage of the } \\
\text { Bayesian regularization algo- } \\
\text { rithm is that it generally takes } \\
\text { more time to converge than } \\
\text { early stopping. }\end{array}$ \\
\hline 2. & 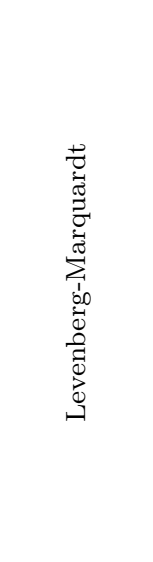 & $\begin{array}{l}\text {-Because of the properties of } \\
\text { the fast convergence and sta- } \\
\text { bility, this method is employed } \\
\text { in many modeling problems. }\end{array}$ & $\begin{array}{l}\bullet \text { One of the main drawbacks } \\
\text { of the LM algorithm is that it } \\
\text { needs the large storage of some } \\
\text { matrices, for certain problems. } \\
\text { - LM algorithm is really depen- } \\
\text { dent on the initial predictions } \\
\text { for the network parameters. } \\
\text {-Based on the initial weights } \\
\text { of the network, this algorithm } \\
\text { may converge to the local min- } \\
\text { ima or do not converge at all. } \\
\text { - The Levenberg-Marquardt is } \\
\text { very sensitive to the initial net- } \\
\text { work weights. It also does } \\
\text { not consider outliers in the } \\
\text { data, which may lead to overfit- } \\
\text { ting noise. }\end{array}$ \\
\hline
\end{tabular}




\section{Neural Network World 1/2017, 139-178}

3

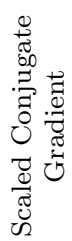

4.

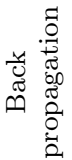

5.

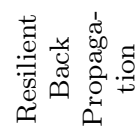

6.

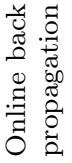

7.

8.
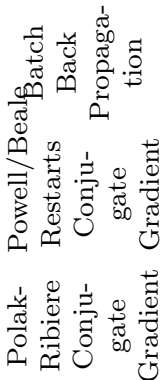

10.

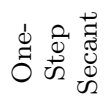

11.

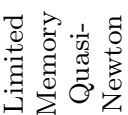

-The SCG algorithm avoids the time-consuming line search.

-The calculation complexity and memory consumption of the SCG algorithm are also low.

-Hence, the speed-up rate of the SCG algorithm is really high.

- Back propagation is a very simple and efficient method for computing the gradient in the NN.

-It is generally much faster than the standard steepest descent algorithm.

- The memory requirements are also moderate.

-The online back propagation algorithm improves the generalization capacity and shows the good convergence speed.

-Further, the online back propagation is superior to the batch back propagation, when there is a maximum degree of redundancy in the training data.

-This is used for the dynamic environments that provide a continuous stream of data values.

-Batch back propagation yields a highly stable descent to the local minimum.

-The performance of the Beale-Powell restart algorithm is higher than the conjugate gradient back propagation.

-Highly effective and suitable for solving large-scale nonsmooth and free convex optimization problems.

-Requires low storage and computation requirements, when compared to the QuasiNewton algorithm.

- The Limited Memory QuasiNewton method requires low memory and less computational time.
- The SCG algorithm does not perform the line search during every iteration.

-Slow rate of convergence.

- The learning time of the back propagation algorithm increases and recall performance reduces, with the increase in the size and complexity of data.

-However, the learning speed and convergence rate are moderate for the artificial hyperbolic test functions.

-The computational complexity of the online back propagation algorithm is high.

-It requires a much longer time to converge, as it considers the total training error over all the patterns.

- The storage requirements for the Powell-Beale algorithm are higher than the storage requirements for Polak-Ribiére.

- The storage requirements for the Polak-Ribiére are slightly larger for Fletcher-Reeves.

- There is no guaranteed error bound for the computed iterations.

- The convergence rate is slower than the Newton algorithms.

- However, the Limited Memory Quasi-Newton method still needs to solve subproblems at every iteration. 
Usha T.M., Appavu alias Balamurugan S.: Computational modeling of electricity...

12

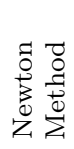

13.

14.

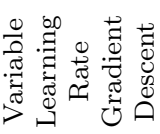

15.

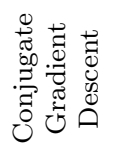

16.

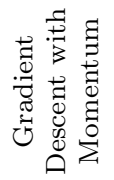

17.

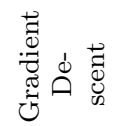

-Newton's method exhibits faster convergence rate than the conjugate gradient approaches.

-This method generalizes more easily for solving the simultaneous types of nonlinear equations.

-Quasi-Newton methods are chosen, since it does not require computation of the Hessian matrix.

-Quasi-Newton Method is much faster than the steepest decant method.

-Convergence rate of this method is superlinear.

-A near-optimal learning rate is obtained for the local terrain.

- The convergance rate is faster than the gradient descent algorithm.

-The conjugate gradient algorithms are usually much quicker than the variable learning rate backpropagation.

-Gradient Descent with Momentum yields better prediction accuracy without requiring more training time.

-With the usage of momentum, the stability of the algorithm is maintained during the higher learning rate.

-Gradient descent is much more faster.
-Unfortunately, it is more complex and really expensive for computing the Hessian matrix for the NNs.

-The problem with this approach is the requirement of computation and storage of the approximate Hessian matrix for every iteration.

-However, this algorithm becomes unstable, if the learning rate is made too large. On the other hand, if the learning rate is set to be too small, the algorithm will take a longer time to converge.

-The time consuming line search is required during all the iterations of the weight update.

-The results are not accurate, due to the low prediction capability.

- Convergence rate is low.

- Not invariant to the linear transformations.

Tab. II Advantages and disadvantages of NN training algorithms.

\section{Dataset description}

This section describes the dataset used in our work. Tab. III shows the units and descriptions of the target variable. Tab. IV shows the units and descriptions of the input variables and. Tab. V shows the economic based information and Electricity consumption data for 50 years.

The economic information and electricity consumption data of Tamilnadu from 1964 to 2013 are collected from the Tamil Nadu Electricity Board (TNEB) and Department of Economics and Statistical department, Tamilnadu, India. The experiment utilizes a $\mathrm{NN}$ with the economic input factors that influence the electric energy consumption as input variables. 
Neural Network World 1/2017, 139-178

\begin{tabular}{cllc}
\hline Variable & $\begin{array}{l}\text { Target } \\
\text { Variable }\end{array}$ & Simple Description & Units \\
\hline$Y 1$ & $\begin{array}{l}\text { Electricity } \\
\text { Consump- }\end{array}$ & $\begin{array}{l}\text { Electricity Consumption is a measure Million Units } \\
\text { of the consumption rate of electric en- } \\
\text { tion }\end{array}$ & $\begin{array}{l}\text { ergy by the consumers during the pe- } \\
\text { riod of year. It is measured in kwh. } \\
\\
\end{array}$ \\
& The electricity consumption is used as \\
& target variable to be forecast in the neu- \\
& ral network.
\end{tabular}

Tab. III Units and description of target variable.

The economic input factors that influence the electricity consumption is selected as the input variables. The economic input variables include the following: population, wholesale price index, urban consumer price index, rural consumer price index, gross state domestic product, state per capita income, exports, imports and industries income. Electricity consumption is the target variable or the dependent variable. The input variables are the independent variables that are used to train the NN to obtain the electricity consumption.

Every independent variable is a time series data belonging to particular economic factors. With the multi-layer perceptron, the parameters of $\mathrm{NN}$ are modified in such a way to obtain maximum similarity between inputs and outputs for all training data. The training data is fed at the network input. For every pattern, the error between the desired and actual network output is analyzed. Depending on the value of this error, correction of the neural weights is performed. The process is repeated until certain conditions of training termination are achieved. The results are obtained using an optimal architecture with different training algorithm and with a different combination of input and output activation functions. The results are compared based on the lowest relative error and highest correlation coefficient.

Tab. VI shows the correlation coefficient of the input variable to the target variable. The table indicates that all the selected input variables have the highest correlation coefficient with the dependent variable. From the correlation coefficient values, it is confirmed that the selected economic-based input variables influence the dependent variable. So, these input variables are the optimal input variables for the NN model.

Tab. VII illustrates the correlation coefficient for different NN architectures. From the table, it is clearly evident that the NN architecture 9-6-5-1 has the highest correlation coefficient than the other NN architectures. Hence, this NN architecture is chosen and trained by using the best training algorithm for the effective computation of electricity consumption. The electricity consumption is measured in Megawatt [MW]. Over the years, there is a constant increase in the electricity consumption rate. 
Usha T.M., Appavu alias Balamurugan S.: Computational modeling of electricity...

\begin{tabular}{|c|c|c|c|}
\hline Variable & Input Variables & Description & Units \\
\hline$X 1$ & Population & $\begin{array}{l}\text { With the increase in the pop- } \\
\text { ulation growth, consumption of } \\
\text { electric energy for the routine ac- } \\
\text { tivities also increases. }\end{array}$ & $\begin{array}{l}\text { Number } \\
\text { of personnel }\end{array}$ \\
\hline$X 2$ & $\begin{array}{l}\text { Wholesale price } \\
\text { index }\end{array}$ & $\begin{array}{l}\text { The Wholesale Price Index } \\
\text { (WPI) represents the special } \\
\text { price of goods that are sold } \\
\text { in bulk and traded between } \\
\text { the organizations, instead of } \\
\text { individual consumers. }\end{array}$ & $\begin{array}{l}\text { Index } \\
\text { Numbers }\end{array}$ \\
\hline$X 3$ & $\begin{array}{l}\text { Consumer } \\
\text { price index } \\
\text { - Urban }\end{array}$ & $\begin{array}{l}\text { The Consumer Price Index } \\
(\mathrm{CPI}) \text { measures the changes } \\
\text { in the price level of consumer } \\
\text { goods and services purchased }\end{array}$ & $\begin{array}{l}\text { Index } \\
\text { Numbers }\end{array}$ \\
\hline$X 4$ & $\begin{array}{l}\text { Consumer } \\
\text { price index } \\
- \text { Rural }\end{array}$ & $\begin{array}{l}\text { by the households. It is a } \\
\text { comprehensive measure used for } \\
\text { approximating the price changes } \\
\text { of the commodities. }\end{array}$ & \\
\hline$X 5$ & $\begin{array}{l}\text { Gross State } \\
\text { Domestic Product }\end{array}$ & $\begin{array}{l}\text { The Gross State Domestic Prod- } \\
\text { uct (GSDP) is a measure of the } \\
\text { economic output of the nation. } \\
\text { It represents the total amount } \\
\text { of productivity of goods and ser- } \\
\text { vices during a year. }\end{array}$ & $\begin{array}{l}\text { Amount } \\
\text { of Money }\end{array}$ \\
\hline$X 6$ & $\begin{array}{l}\text { State Per Capita } \\
\text { Income }\end{array}$ & $\begin{array}{l}\text { State per capita income is de- } \\
\text { fined as the average income of in- } \\
\text { dividuals in a state. }\end{array}$ & $\begin{array}{l}\text { Amount } \\
\text { of Money }\end{array}$ \\
\hline$X 7$ & Exports & $\begin{array}{l}\text { Export is the process of selling } \\
\text { goods and services produced in } \\
\text { the home country to the Inter- } \\
\text { national markets. }\end{array}$ & $\begin{array}{l}\text { Amount } \\
\text { of Money }\end{array}$ \\
\hline$X 8$ & Imports & $\begin{array}{l}\text { Import is the process of the re- } \\
\text { ceiving goods and services from } \\
\text { an external producer. }\end{array}$ & $\begin{array}{l}\text { Amount } \\
\text { of Money }\end{array}$ \\
\hline$X 9$ & $\begin{array}{l}\text { Industrial } \\
\text { income }\end{array}$ & $\begin{array}{l}\text { Industrial income is the total } \\
\text { amount of income incurred by } \\
\text { the industries. }\end{array}$ & $\begin{array}{l}\text { Amount } \\
\text { of Money }\end{array}$ \\
\hline
\end{tabular}

Tab. IV Units and description of input variables.

\section{Results and discussion}

This section explains the comparative analysis of the NN training algorithms. Among these training algorithms, the optimal training algorithm is determined. 
Neural Network World 1/2017, 139-178

\begin{tabular}{|c|c|c|c|c|c|c|c|c|c|}
\hline Year & $\begin{array}{c}\text { Population } \\
\text { (Number) }\end{array}$ & \begin{tabular}{|c|} 
Whole \\
sale \\
price \\
index \\
- Number
\end{tabular} & $\begin{array}{c}\text { Consumer } \\
\text { price } \\
\text { index - } \\
\text { Urban } \\
\text {-Number }\end{array}$ & $\begin{array}{c}\text { Consumer } \\
\text { price } \\
\text { index - } \\
\text { Rural } \\
\text {-Number }\end{array}$ & \begin{tabular}{|c|} 
Gross \\
State \\
Domestic \\
Product \\
-Lakhs
\end{tabular} & \begin{tabular}{|c|} 
State \\
Per \\
Capita \\
Income \\
-Lakhs
\end{tabular} & $\begin{array}{l}\text { Export } \\
\text {-Lakhs }\end{array}$ & $\begin{array}{l}t \\
s\end{array}$ & $\begin{array}{l}\text { Industry } \\
\text { income } \\
\text {-Lakhs }\end{array}$ \\
\hline 1904 & & & & & & & & & \\
\hline 1965 & & & & & & & & & \\
\hline 1966 & 47 & & & & & & & & \\
\hline 1967 & 3539327 & & & & & & & & \\
\hline 1968 & & & & & & & & & \\
\hline 1969 & & & & & & & & & \\
\hline 1970 & & & & & & & & 792 & \\
\hline 1971 & & & & & & & & & \\
\hline 1972 & & & & & & & & & \\
\hline 1973 & 26 & 149.02 & & & & & & & \\
\hline 1974 & & & & & & & & & \\
\hline 1975 & & & & & & & & & \\
\hline 1976 & & 166.37 & & & & & & & \\
\hline 1977 & & & & & & & & & \\
\hline 1978 & & & & & & & & & \\
\hline 1979 & & & & & & & & & \\
\hline 1980 & & & & & & & & & \\
\hline 1981 & & & & & & & & & \\
\hline 1982 & & 73 & & & & & & & \\
\hline 1983 & & & & & & & & & \\
\hline 1984 & & & & & & & & & \\
\hline 1985 & & & & & & 27 & & & \\
\hline 1986 & & & & & & & & & \\
\hline 1987 & & & & & & & & & \\
\hline 1988 & & & & & 71 & & & & \\
\hline 1989 & & & & & & & & & \\
\hline 1990 & & & & & & & & & \\
\hline 1991 & & & & & & & & & \\
\hline 1992 & & & & & & & & & \\
\hline 1993 & 822 & & & & 22 & & & & \\
\hline 1994 & & & & & & & & & \\
\hline 1995 & & & & & & 6 & & 72 & \\
\hline 1996 & & & & & & & & & \\
\hline 1997 & & & & & & & & & \\
\hline 1998 & & & & & & & & & \\
\hline 1999 & & & & & 616 & & & & \\
\hline 2000 & & & & & & & & & \\
\hline 2001 & 9 & .77 & 34 & 4 & 56 & 29 & 24 & 05 & 00 \\
\hline 2002 & & & & & & & & & \\
\hline 2003 & & & & & 087 & & & 00 & \\
\hline 2004 & & .00 & 76 & & 415 & 76 & 00 & 00 & 700 \\
\hline 2005 & 42 & 3.00 & .12 & & 287 & 25965 & 800 & 8300 & 100 \\
\hline 2006 & & & & & 283 & & & 3500 & \\
\hline 2007 & & \begin{tabular}{|l|}
1451.00 \\
\end{tabular} & 5.72 & 49 & 6587 & 37635 & 9176200 & 19016100 & \\
\hline 2008 & & & & & 28746 & 36915 & 0300 & 23098700 & 3971400 \\
\hline 2009 & & & & & 192 & & 300 & 600 & \\
\hline 2010 & & 7.00 & 78.3 & 2.38 & 164 & & & 100 & \\
\hline 2011 & 71328846 & \begin{tabular}{|l|}
1798.00 \\
\end{tabular} & 2122.67 & & \begin{tabular}{|l|}
42491835 \\
\end{tabular} & 70219 & 9060300 & 23098700 & 7695600 \\
\hline 2012 & & 00 & & & 62 & & 300 & 600 & 9136400 \\
\hline 2013 & 1874302 & 204.00 & 623.07 & 2770.16 & 63902460 & 84496 & 11309300 & 28906600 & 9576510 \\
\hline
\end{tabular}

Tab. V Economic based information and electricity consumption data for 50 years. 
Usha T.M., Appavu alias Balamurugan S.: Computational modeling of electricity...

\begin{tabular}{clc}
\hline S. No & Input Variables & Correlation coefficients \\
\hline 1 & Population & 0.940 \\
2 & Wholesale price index & 0.982 \\
3 & Urban - Consumer price index & 0.978 \\
4 & Rural - Consumer price index & 0.977 \\
5 & Gross State Domestic Product & 0.916 \\
6 & State Per Capita Income & 0.875 \\
7 & Exports & 0.906 \\
8 & Imports & 0.859 \\
9 & Industries income & 0.978 \\
\hline
\end{tabular}

Tab. VI Correlation coefficients of the input variables to the target variable.

\begin{tabular}{cc}
\hline NN architectures & Correlation coefficient \\
\hline$[9-3-5-1]$ & 0.940274 \\
{$[9-4-5-1]$} & 0.998368 \\
{$[9-5-5-1]$} & 0.897638 \\
{$[9-6-5-1]$} & 0.999982 \\
{$[9-7-5-1]$} & 0.996277 \\
\hline
\end{tabular}

Tab. VII Correlation Coefficient for different NN architectures.

Alyuda NeuroIntelligence 2.1 software [1] and MATLAB 2013b software [29] are utilized for experimentation. The comparative analysis of the relative error and correlation coefficient of the training algorithms with different combinations of the activation functions is carried out in this section. The dataset involves the electricity consumption data for 50 years. The dataset is partitioned into two sets of data for training and testing. The dataset is partitioned into two sets of data for training and testing. 90\% of data is used for training and $10 \%$ is used for testing. Tab. VIII shows the comparative analysis of the correlation coefficient of every training algorithm. The comparative analysis of the relative error of each NN training algorithm is shown in the Tab. IX. Tab. X shows the ranking of the NN training algorithms based on relative error and correlation coefficient.

\subsection{Relative error}

The Relative Error (RE) is obtained by dividing the difference between the actual and the desired output values. It is calculated by using the following equation

$$
\mathrm{RE}=\left(\frac{1}{N} \sum_{i}^{N} \frac{\left|Y_{i}-Y_{p}\right|}{Y_{p}}\right) \times 100
$$


where $Y_{i}$ represents the mean value of the NN output, $Y_{p}$ is the predicted value of the NN output and $N$ represents the number of cases used for the calculations of statistical parameters.

\subsection{Correlation coefficient}

The correlation coefficient is defined as the degree of the relationship between the input and output variables. The values of the correlation coefficient ranges from -1.0 to 1.0. If the correlation coefficient is +1.0 , there is a high positive correlation between the variables. If the correlation coefficient is -1.0 , there is a high negative correlation between the variables. If it is equal to 0 , it denotes the non-correlation between the variables.

Fig. 7 shows the graph illustrating the comparison between the correlation coefficients for NN training algorithms. The correlation coefficient of the Bayesian Regularization training algorithm is higher than other training algorithms. Fig. 8 shows the comparison graph of the relative error values of every training algorithm. The relative error of the Bayesian Regularization training algorithm is 0.000257 , which is the lowest value among the relative error of other training algorithms. Hence, the Bayesian Regularization training algorithm is selected as the optimal training algorithm for the effective computation of the electricity consumption. It creates the computing model to predict the electricity consumption using the nine economical quantities.

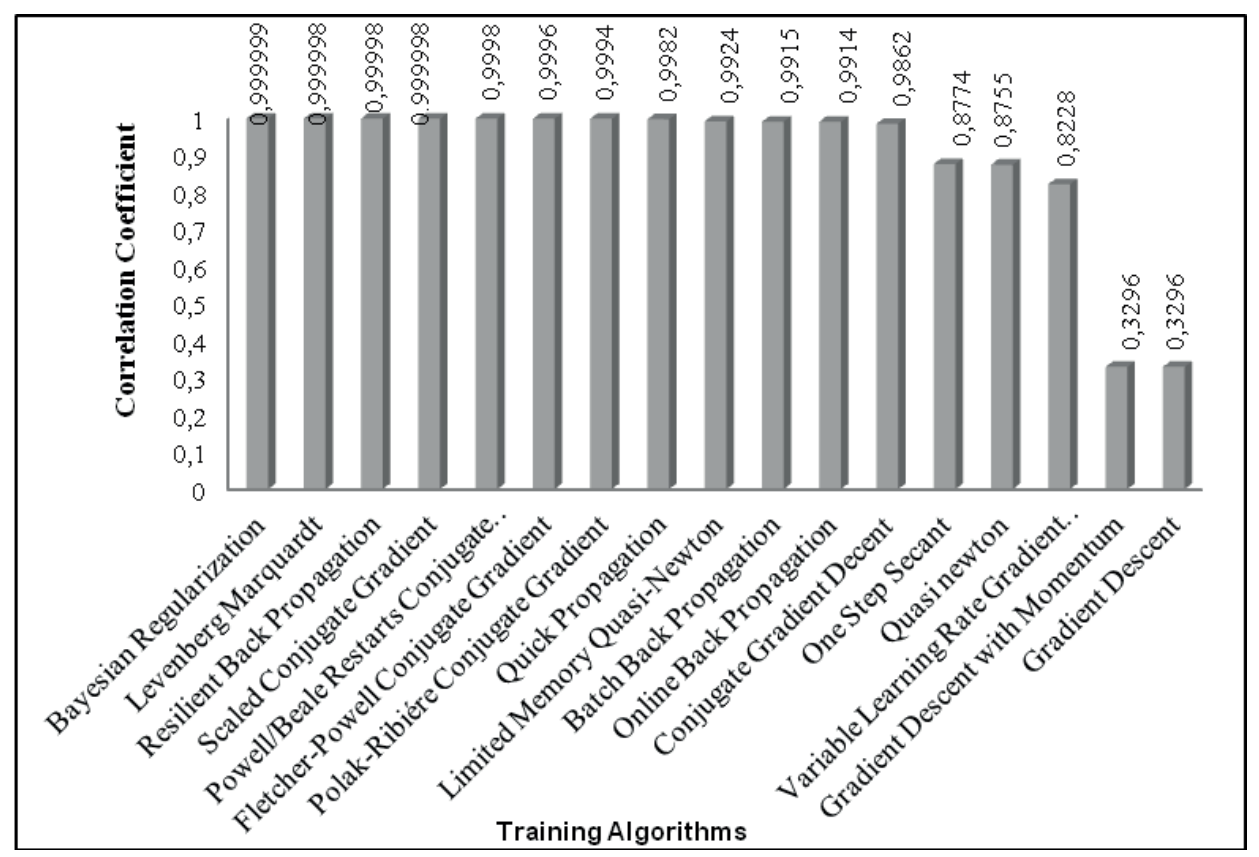

Fig. 7 Correlation coefficient analysis for the NN training algorithms. 


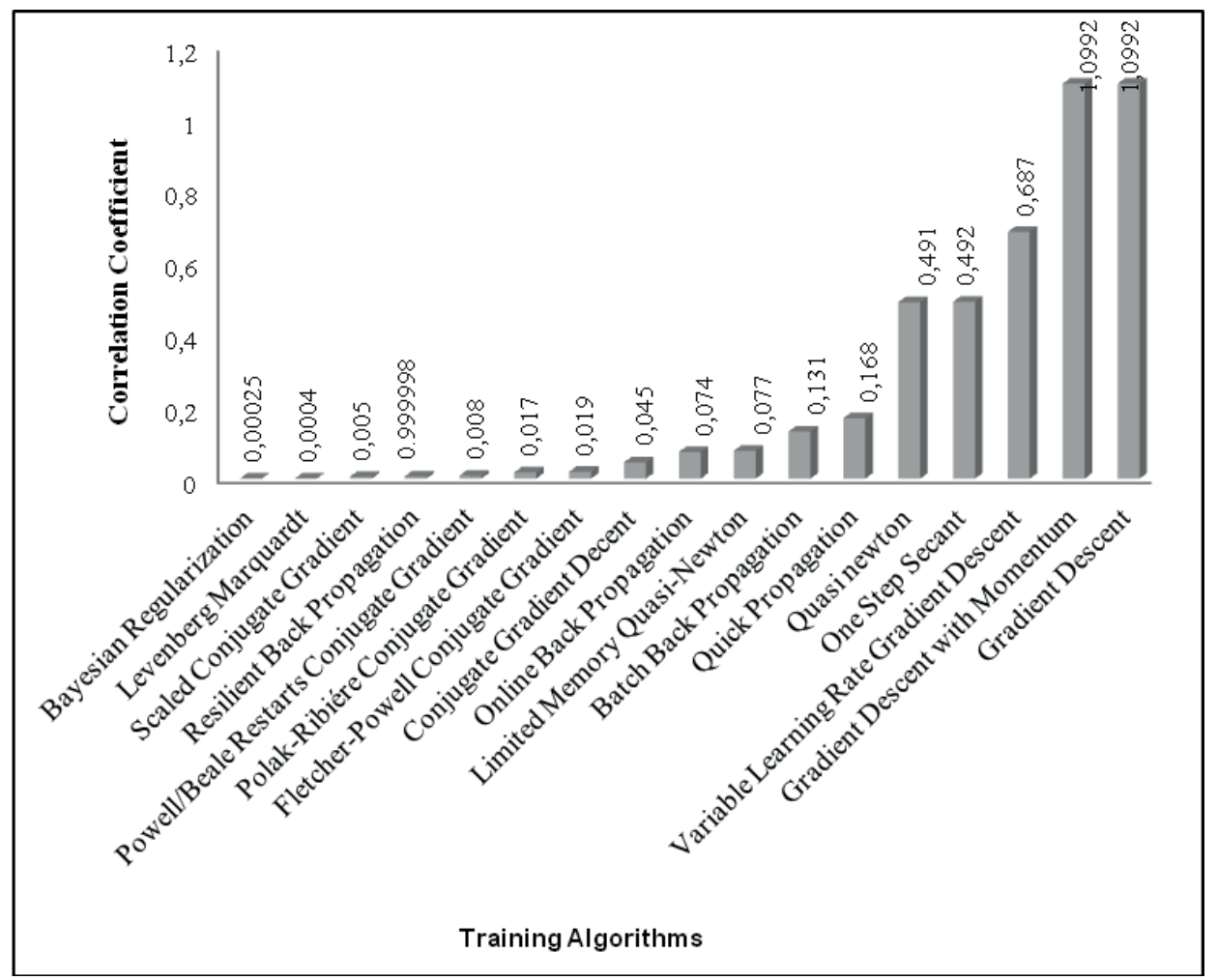

Fig. 8 Relative Error of each training algorithm.

The comparative analysis of correlation coefficient of every NN training algorithm with different combinations of the activation function is shown in Tab. VIII. From the table, it is clearly observed that the correlation coefficient of the Hyperbolic Tangent - Hyperbolic Tangent of the Bayesian Regularization training algorithm is found to be the highest, among all the other activation functions.

The comparative analysis of the relative error of every training algorithm with different combinations of the activation function is depicted in Tab. IX. The relative error of the Hyperbolic Tangent-Hyperbolic Tangent activation function of the Bayesian Regularization training algorithm is found to be the lowest, among all the other activation functions.

This implies that the Bayesian Regularization training algorithm is the optimal training algorithm for the electricity consumption forecasting. The ranking of the training algorithms based on the accuracy parameter is shown in the Tab. X. Based on the lower relative error and higher correlation coefficient in both the training and testing period, the Bayesian Regularization training algorithm obtains the highest rank. The Levenberg Marquardt training algorithm is ranked second. It accurately predicts the electricity demand rate more closely to the actual data. This means that the deviation of the predicted electricity demand rate from the actual demand rate is minimum. Hence, it is concluded that the Bayesian Regularization 
training algorithm is determined as the optimal training algorithm for the effective computation of electricity consumption.

\begin{tabular}{|c|c|c|c|c|c|c|c|c|c|}
\hline 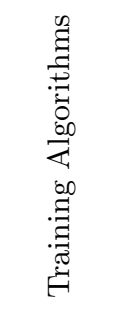 & 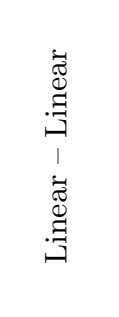 & 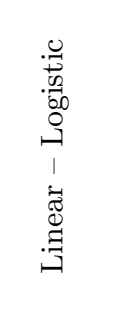 & 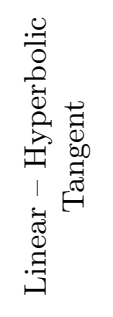 & 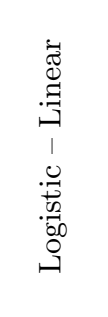 & 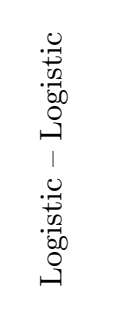 & 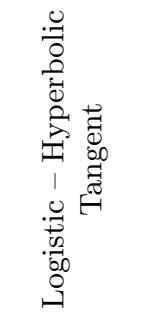 & 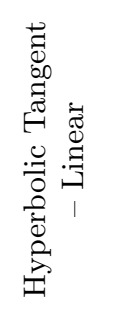 & 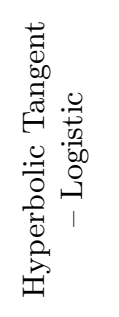 & 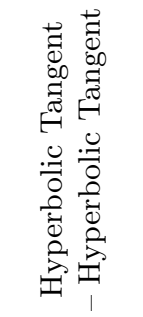 \\
\hline QN & 0.9985 & 0.8656 & 0.9942 & 0.9993 & 0.8565 & 0.99996 & 0.999 & 0.8011 & 0.8774 \\
\hline LM-QN & 0.9951 & 0.9975 & 0.9973 & 0.993 & 0.9714 & 0.9905 & 0.9947 & 0.9897 & 0.9915 \\
\hline OSS & 0.9982 & 0.8667 & 0.8555 & 0.9994 & 0.8565 & 0.9835 & 0.9993 & 0.7411 & 0.8755 \\
\hline $\mathrm{LM}$ & 0.9985 & 0.8656 & 0.9942 & 0.9982 & 0.8603 & 0.99997 & 0.9996 & 0.8684 & 0.999998 \\
\hline $\mathrm{BR}$ & 0.9987 & 0.858 & 0.9943 & 0.9998 & 0.8881 & 0.99999 & 0.9998 & 0.8692 & 0.999999 \\
\hline $\mathrm{QP}$ & 0.9971 & 0.9878 & 0.9866 & 0.9573 & 0.9818 & 0.8035 & 0.9897 & 0.9983 & 0.9862 \\
\hline OBP & 0.9952 & 0.9974 & 0.9966 & 0.9442 & 0.9699 & 0.982 & 0.9904 & 0.9987 & 0.9924 \\
\hline $\mathrm{BBP}$ & 0.9981 & 0.9975 & 0.991 & 0.9929 & 0.9713 & 0.9904 & 0.9938 & 0.9889 & 0.9914 \\
\hline $\mathrm{RBP}$ & 0.9986 & 0.8657 & 0.9943 & 0.9995 & 0.8685 & 0.99998 & 0.9992 & 0.8668 & 0.9999 \\
\hline CGD & 0.9981 & 0.9982 & 0.9982 & 0.9574 & 0.9982 & 0.9982 & 0.9757 & 0.9897 & 0.9982 \\
\hline SCG & 0.9984 & 0.8666 & 0.9945 & 0.9992 & 0.9945 & 0.99999 & 0.9987 & 0.8561 & 0.99998 \\
\hline FPCG & 0.9979 & 0.8661 & 0.9944 & 0.9988 & 0.8774 & 0.9987 & 0.9989 & 0.8521 & 0.9994 \\
\hline PRCG & 0.9983 & 0.8654 & 0.9943 & 0.9989 & 0.8565 & 0.9954 & 0.9989 & 0.8411 & 0.9996 \\
\hline PBRCG & 0.9976 & 0.8658 & 0.9942 & 0.999 & 0.8774 & 0.9948 & 0.9989 & 0.8566 & 0.9998 \\
\hline VLRGD & 0.9987 & 0.8865 & 0.9946 & 0.9994 & 0.8565 & 0.9994 & 0.9993 & 0.8041 & 0.8228 \\
\hline GDM & 0.0381 & 0.2356 & 0.1831 & 0.2913 & 0.2451 & 0.3296 & 0.2893 & 0.2451 & 0.3296 \\
\hline GD & 0.0381 & 0.2356 & 0.1831 & 0.2913 & 0.2451 & 0.3296 & 0.2893 & 0.2451 & 0.3296 \\
\hline
\end{tabular}

Tab. VIII Comparative analysis of correlation coefficient of each training algorithm with different combinations of activation functions.

\subsection{WEKA time series analysis}

After finding an optimal training algorithm, the future electricity consumption is to be forecasted. For further forecasting of electricity consumption, all 9 economical quantities are needed. Since all the variables are time dependent, a Waikato Environment for Knowledge Analysis-version (WEKA) based time series forecasting can be done for every input variable. A WEKA-version 3.7.6 (WEKA 3.7.6) tool [16] is used for time series forecasting. The time series forecasting is reliable for the data that represents the long-time predictions. It can be used easily as the historical observations are readily available from secondary sources. These successive observations are statistically dependent. The time series forecasting is concerned with the analysis of statistical dependencies. 


\begin{tabular}{|c|c|c|c|c|c|c|c|c|c|}
\hline 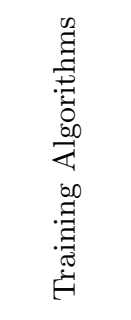 & 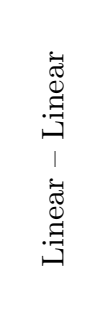 & 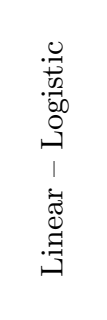 & 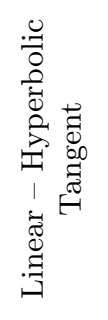 & 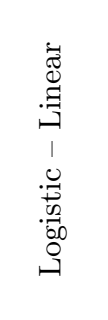 & 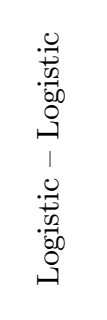 & 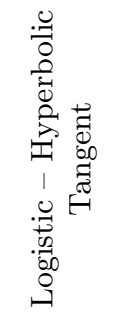 & 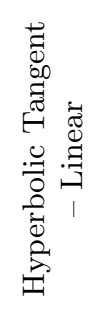 & 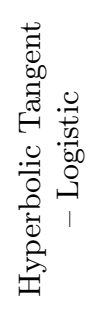 & 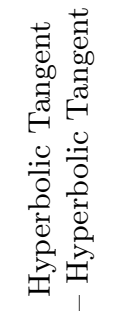 \\
\hline $\mathrm{QN}$ & 0.038 & 2.075 & 0.498 & 0.029 & 2.143 & 0.211 & 0.036 & 2.143 & 0.491 \\
\hline LM-QN & 0.031 & 1.848 & 0.071 & 0.427 & 1.732 & 0.058 & 0.094 & 1.922 & 0.077 \\
\hline OSS & 0.045 & 2.076 & 0.183 & 0.035 & 2.143 & 0.009 & 0.034 & 2.143 & 0.492 \\
\hline LM & 0.046 & 2.075 & 0.182 & 0.062 & 2.081 & 0.001 & 0.033 & 2.073 & 0.0004 \\
\hline $\mathrm{BR}$ & 0.047 & 2.091 & 0.184 & 0.0163 & 2.084 & 0.00027 & 0.016 & 2.089 & 0.00025 \\
\hline QP & 0.043 & 1.715 & 0.101 & 0.099 & 1.418 & 0.086 & 0.377 & 1.133 & 0.168 \\
\hline OBP & 0.033 & 1.814 & 0.08 & 0.08 & 1.132 & 0.111 & 0.046 & 1.915 & 0.074 \\
\hline $\mathrm{BBP}$ & 0.049 & 1.939 & 0.087 & 0.08 & 1.232 & 0.111 & 0.07 & 1.769 & 0.131 \\
\hline RBP & 0.047 & 2.076 & 0.189 & 0.048 & 0.189 & 0.004 & 0.051 & 2.079 & 0.006 \\
\hline CGD & 0.056 & 1.812 & 0.09 & 0.32 & 1.348 & 0.201 & 0.088 & 1.832 & 0.045 \\
\hline SCG & 0.049 & 2.075 & 0.185 & 0.029 & 2.073 & 0.003 & 0.036 & 2.073 & 0.005 \\
\hline FPCG & 0.037 & 2.076 & 0.184 & 0.048 & 2.077 & 0.116 & 0.041 & 2.082 & 0.019 \\
\hline PRCG & 0.044 & 2.076 & 0.186 & 0.047 & 2.074 & 0.037 & 0.041 & 2.09 & 0.017 \\
\hline PBRCG & 0.044 & 2.076 & 0.182 & 0.044 & 2.074 & 0.132 & 0.042 & 2.078 & 0.008 \\
\hline VLRGD & 0.046 & 2.087 & 0.192 & 0.031 & 2.143 & 0.038 & 0.036 & 2.143 & 0.687 \\
\hline GDM & 22.216 & 2.1031 & 3.7297 & 2.0783 & 2.1431 & 1.0992 & 1.9652 & 2.1431 & 1.0992 \\
\hline GD & 22.216 & 2.1031 & 3.7297 & 2.0783 & 2.1431 & 1.0992 & 1.9652 & 2.1431 & 1.0992 \\
\hline
\end{tabular}

Tab. IX Comparative analysis of relative error of each training algorithm with different combinations of activation functions.

In the time series forecasting, the prediction of the future values does not depend on the explanatory variables that affect the system. As the collection of information on the explanatory variables is highly cumbersome, there is a problem in the availability of long-term data. In such conditions, the time series model is a boon for forecasting.

Tab. XI shows the Forecasting of input variable using WEKA Time Series Analysis for the next 15 years. Time series forecasting uses a model to predict the future values based on previously observed values. The forecasted time series data is applied to the computational model to predict the electricity consumption of next 15 years. Tab. XII shows the prediction of the electricity consumption using the Bayesian Regularization training algorithm. The electricity consumption is measured in Megawatt (MW). Fig. 9 shows the predicted electricity consumption using Bayesian regularization training algorithm for the 2014-2028. Fig. 10 shows the actual and predicted electricity consumption. From the graph, it is observed that there is a linear increase in the acutal and predicted electricity consumption from the year 1964 to 2028 . 


\begin{tabular}{|c|c|c|c|c|c|c|c|}
\hline 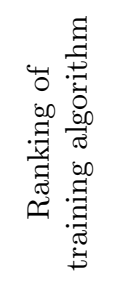 & 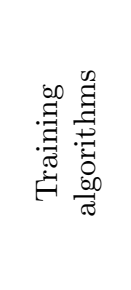 & 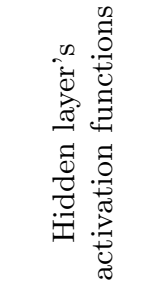 & 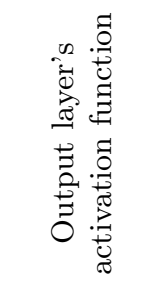 & 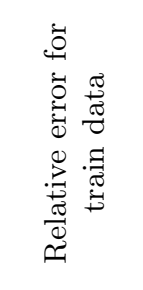 & 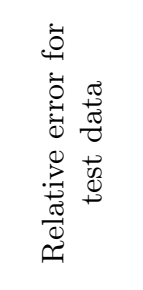 & 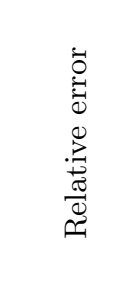 & 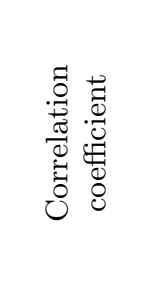 \\
\hline Rank 1 & $\mathrm{BR}$ & Hyp. Tan. & Hyp. Tan. & 0.000305 & 0.000004 & 0.00025 & 0.999999 \\
\hline Rank 2 & LM & Hyp. Tan. & Hyp. Tan. & 0.000346 & 0.00069 & 0.00040 & 0.999998 \\
\hline Rank 3 & SCG & Logistic & Hyp. Tan. & 0.00278 & 0.0024 & 0.00268 & 0.999984 \\
\hline Rank 4 & $\mathrm{RBP}$ & Logistic & Hyp. Tan. & 0.00528 & 0.0008 & 0.00411 & 0.999994 \\
\hline Rank 5 & PBRCG & Hyp. Tan. & Hyp. Tan. & 0.00749 & 0.00833 & 0.00771 & 0.999803 \\
\hline Rank 6 & OSS & Logistic & Hyp. Tan. & 0.0110 & 0.00289 & 0.00886 & 0.999962 \\
\hline Rank 7 & PRCG & Hyp. Tan. & Hyp. Tan. & 0.0170 & 0.0155 & 0.01658 & 0.999436 \\
\hline Rank 8 & FPCG & Hyp. Tan. & Hyp. Tan. & 0.0204 & 0.0139 & 0.01873 & 0.999626 \\
\hline Rank 9 & LM-QN & Hyp. Tan. & Logistic & 0.0192 & 0.0286 & 0.02164 & 0.998668 \\
\hline Rank 10 & $\mathrm{QN}$ & Logistic & Linear & 0.0337 & 0.0140 & 0.02857 & 0.999434 \\
\hline Rank 11 & VLRGD & Logistic & Linear & 0.0372 & 0.0135 & 0.03103 & 0.999436 \\
\hline Rank 12 & CGD & Hyp. Tan. & Logistic & 0.0221 & 0.0620 & 0.03248 & 0.998281 \\
\hline Rank 13 & $\mathrm{QP}$ & Hyp. Tan. & Logistic & 0.0198 & 0.0721 & 0.03341 & 0.989689 \\
\hline Rank 14 & OBP & Hyp. Tan. & Linear & 1.0063 & 0.0647 & 0.04552 & 0.993832 \\
\hline Rank 15 & $\mathrm{BBP}$ & Hyp. Tan. & Linear & 0.0731 & 0.0597 & 0.06964 & 0.994668 \\
\hline Rank 16 & GDM & Hyp. Tan. & Hyp. Tan. & 1.2715 & 0.6087 & 1.099 & 0.329695 \\
\hline Rank 17 & GD & Hyp. Tan. & Hyp. Tan. & 1.2715 & 0.6087 & 1.099 & 0.329695 \\
\hline
\end{tabular}

Tab. X Ranking of training algorithms based on relative error \& correlation coefficient.

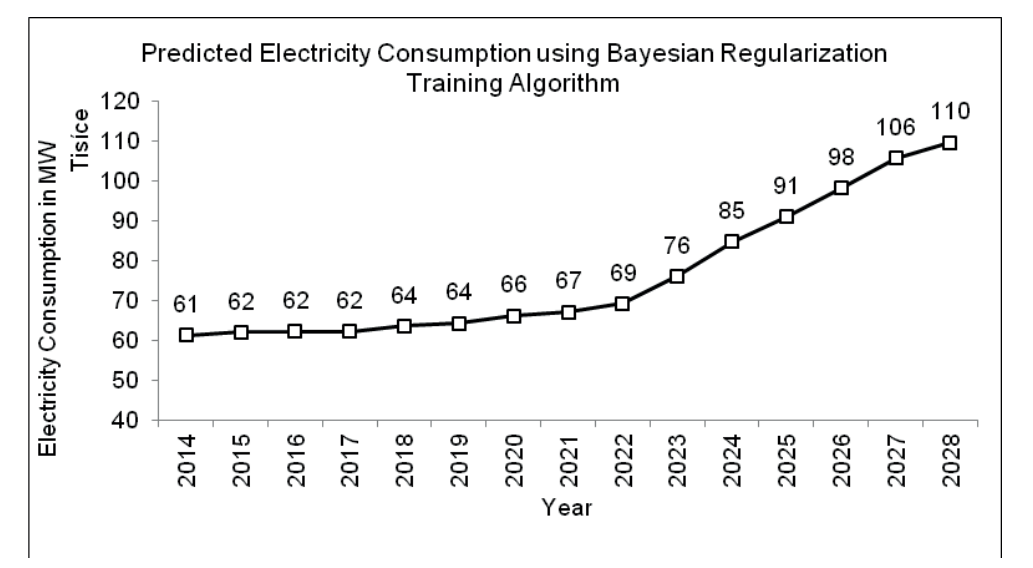

Fig. 9 Predicted electricity consumption using Bayesian regularization training algorithm. 


\begin{tabular}{|c|c|c|c|c|c|c|c|c|c|}
\hline$\stackrel{\mathscr{\varpi}}{\stackrel{\widetilde{J}}{二}}$ & 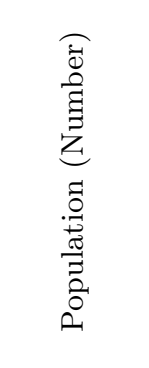 & 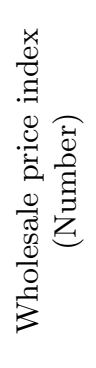 & 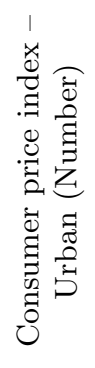 & 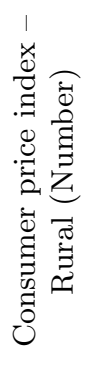 & 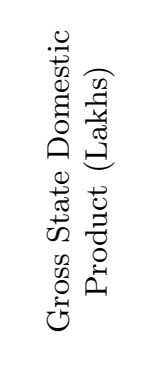 & 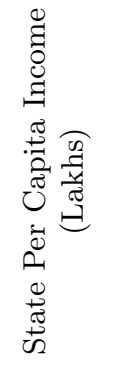 & 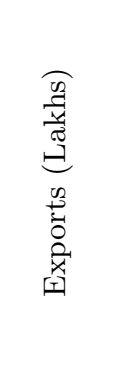 & 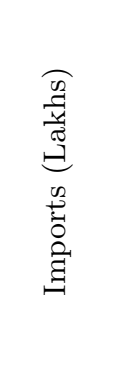 & 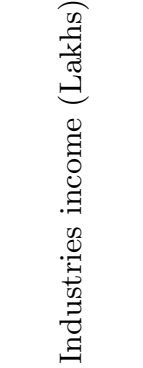 \\
\hline 2014 & 72147030 & 2183 & 2957 & 3173 & 74447610 & 98567 & 11309 & 28906 & 9847770 \\
\hline 2015 & 72419758 & 2684 & 3071 & 3191 & 77467807 & 102819 & 12139 & 30555 & 10274124 \\
\hline 2016 & 72692486 & 2811 & 3223 & 3223 & 81699163 & 117332 & 13623 & 31673 & 10356816 \\
\hline 2017 & 72965214 & 2958 & 3387 & 3387 & 87547989 & 128779 & 15495 & 32381 & 10429978 \\
\hline 2018 & 73237942 & 3145 & 3567 & 3567 & 92735709 & 139659 & 18147 & 33135 & 10597092 \\
\hline 2019 & 73510670 & 3437 & 3888 & 3888 & 99681483 & 155275 & 22796 & 35663 & 10854890 \\
\hline 2020 & 73783398 & 3686 & 4160 & 4160 & 104527870 & 166557 & 26884 & 38114 & 11103548 \\
\hline 2021 & 74056126 & 4115 & 4658 & 4658 & 112559964 & 177413 & 33845 & 41549 & 11520636 \\
\hline 2022 & 74509893 & 4937 & 5544 & 5544 & 132939225 & 197733 & 51681 & 48825 & 12721422 \\
\hline 2023 & 74963660 & 5500 & 6159 & 6159 & 153340199 & 210521 & 72534 & 55944 & 13956157 \\
\hline 2024 & 75417427 & 6552 & 7077 & 7377 & 159871549 & 233739 & 113464 & 71944 & 15720542 \\
\hline 2025 & 75871194 & 7247 & 8357 & 8357 & 162012257 & 256974 & 143161 & 103492 & 18268664 \\
\hline 2026 & 76324961 & 7962 & 9909 & 9909 & 173860266 & 269228 & 160474 & 166963 & 19278201 \\
\hline 2027 & 76778728 & 8798 & 10716 & 10716 & 198558032 & 298993 & 184480 & 184402 & 21719262 \\
\hline 2028 & 77232495 & 9030 & 11218 & 11238 & 206584178 & 319437 & 198051 & 214918 & 22374716 \\
\hline
\end{tabular}

Tab. XI Forecasting of input variable using WEKA Time Series Analysis.

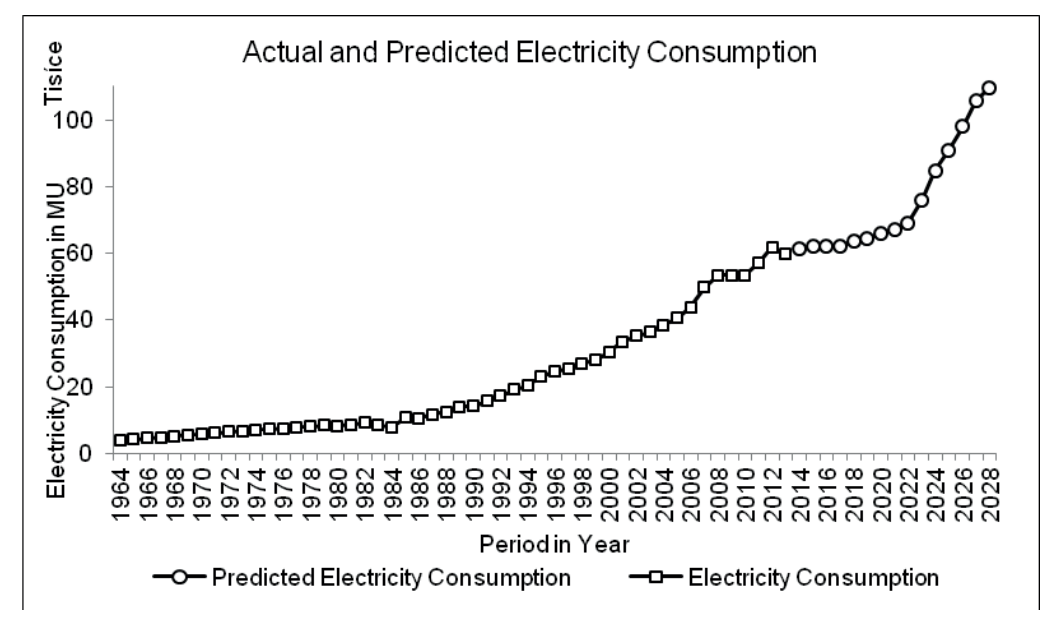

Fig. 10 Actual and Predicted electricity consumption. 
Neural Network World 1/2017, 139-178

\begin{tabular}{cc}
\hline Year & Predicted Electricity Consumption $[\mathrm{MW}]$ \\
\hline 2014 & 61,210 \\
2015 & 61,980 \\
2016 & 62,100 \\
2017 & 62,200 \\
2018 & 63,512 \\
2019 & 64,248 \\
2020 & 66,126 \\
2021 & 67,086 \\
2022 & 69,156 \\
2023 & 76,066 \\
2024 & 84,757 \\
2025 & 91,009 \\
2026 & 98,110 \\
2027 & 105,645 \\
2028 & 109,645 \\
\hline
\end{tabular}

Tab. XII Prediction of electricity consumption using Bayesian Regularization Training Algorithm.

\subsection{Complexity analysis}

The complexity of the NN training algorithms is analyzed by using the training speed, number of iterations and computation time. Tab. VIII shows the computation time of every NN training algorithm. The Bayesian Regularization algorithm requires minimum number of iterations and computation time than other training algorithms.

\subsection{Evaluation using larger dataset}

Different size of datasets such as Energy efficiency dataset [3], Tamilnadu Electricity Board Hourly Readings [21], Individual household electric power consumption dataset [15] are collected from UCI Repository and the Electric bill data [30] is collected from American Statistical Association. They are applied for validating the performance of all NN training algorithms. The missing data is present in an input variable and replaced with the average value of previous and next value of the corresponding input variable. Tab. XIV illustrates the descriptions of UCI and American Statistical Association datasets.

Energy Efficient Dataset comprises of 768 samples and 8 features, to predict two real valued responses such as heating load and cooling load. The features are relative compactness, surface area, wall area, roof area, overall height, orientation, glazing area and glazing area distribution. Tamilnadu Electricity Board Hourly Readings dataset involves the real time readings to find the accuracy consumption of electricity per hour in Tamilnadu around the Thanjavur district. This data is obtained for the residential, commercial, industrial and agriculture applica- 
Usha T.M., Appavu alias Balamurugan S.: Computational modeling of electricity...

\begin{tabular}{cccc}
\hline & \multicolumn{3}{c}{ Metric } \\
\cline { 2 - 4 } Training & $\begin{array}{c}\text { Training Speed } \\
\text { Algorithm }\end{array}$ & $\begin{array}{c}\text { Number of } \\
\text { [iterations/s] }\end{array}$ & $\begin{array}{c}\text { Computation } \\
\text { Time [s] }\end{array}$ \\
\hline QN & 107.03 & 3746 & 35 \\
LM-QN & 485.45 & 30001 & 61.8 \\
OSS & 81.12 & 10059 & 124 \\
LM & 52.95 & 1006 & 19 \\
BR & 51.28 & 923 & 18 \\
QP & 3409.2 & 30001 & 8.8 \\
OBP & 3000.1 & 30001 & 10 \\
BBP & 3658.65 & 30001 & 8.2 \\
RBP & 358.57 & 10040 & 28 \\
CGD & 187.5 & 30001 & 160.01 \\
SCG & 265.42 & 10086 & 38 \\
FPCG & 114 & 114 & 1 \\
PRCG & 143 & 429 & 3 \\
PBRCG & 141 & 141 & 1 \\
VLRGD & 549.1 & 11531 & 21 \\
GDM & 5 & 23 & 4.6 \\
GD & 5 & 21 & 4.2 \\
\hline
\end{tabular}

Tab. XIII Computation time of each NN training algorithm.

tions. Individual household electric power consumption dataset contains 2075259 electric power consumption measurements collected in one household with a oneminute sampling rate between December 2006 and November 2010. Electric Bill dataset involves the household electric bill amount and electricity consumption on a monthly basis presented as a time series for January 1991 through December 2000 .

The optimal splitting proportion is highly important for successful training. Here, the small size dataset is split into $90 \%$ for training and $10 \%$ for testing. The medium size dataset is split into $70 \%$ for training and $30 \%$ for testing. The larger size dataset is split into $60 \%$ for training and $40 \%$ for testing. The relative error and correlation in the prediction of electricity consumption on different size of datasets are calculated using all the NN training algorithms. The results are compared to analyze the prediction accuracy for different size of datasets.

Tab. XV shows the relative error of the NN training algorithms for different sizes of datasets. Fig. 11 depicts the comparison of the relative error for different datasets. The presence of instances and attributes result in the increase in the relative error. The prediction accuracy decreases with the increase in the size of the dataset. From the Tab. XIV, the number of attributes in the proposed econometric variable dataset is lesser than other datasets. Hence, the relative error of the proposed econometric variable dataset is low and prediction accuracy is high. From the Tab. XV it is observed that the Bayesian regularization training algorithm yields lower relative error than other training algorithms. 
Neural Network World 1/2017, 139-178

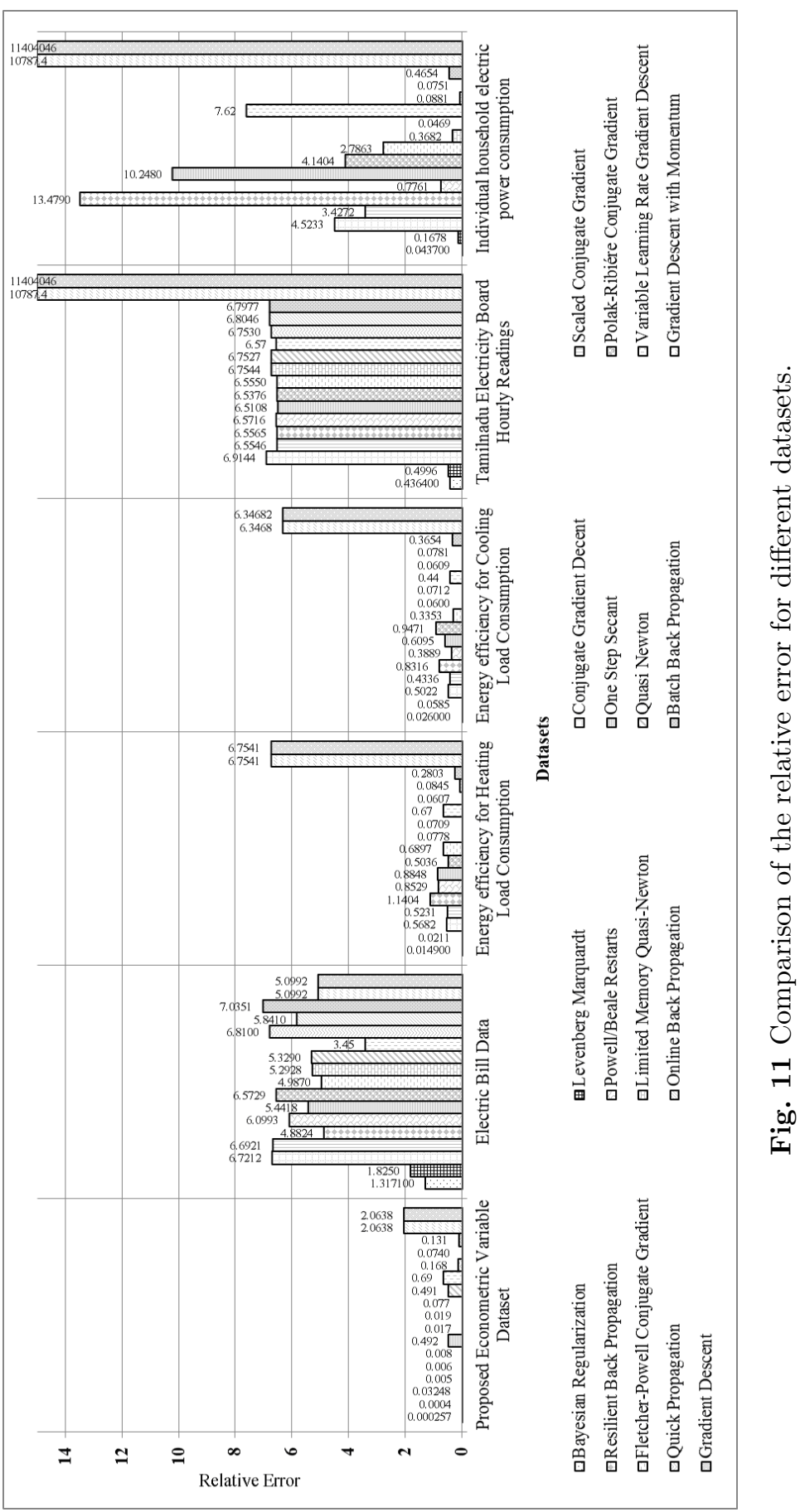




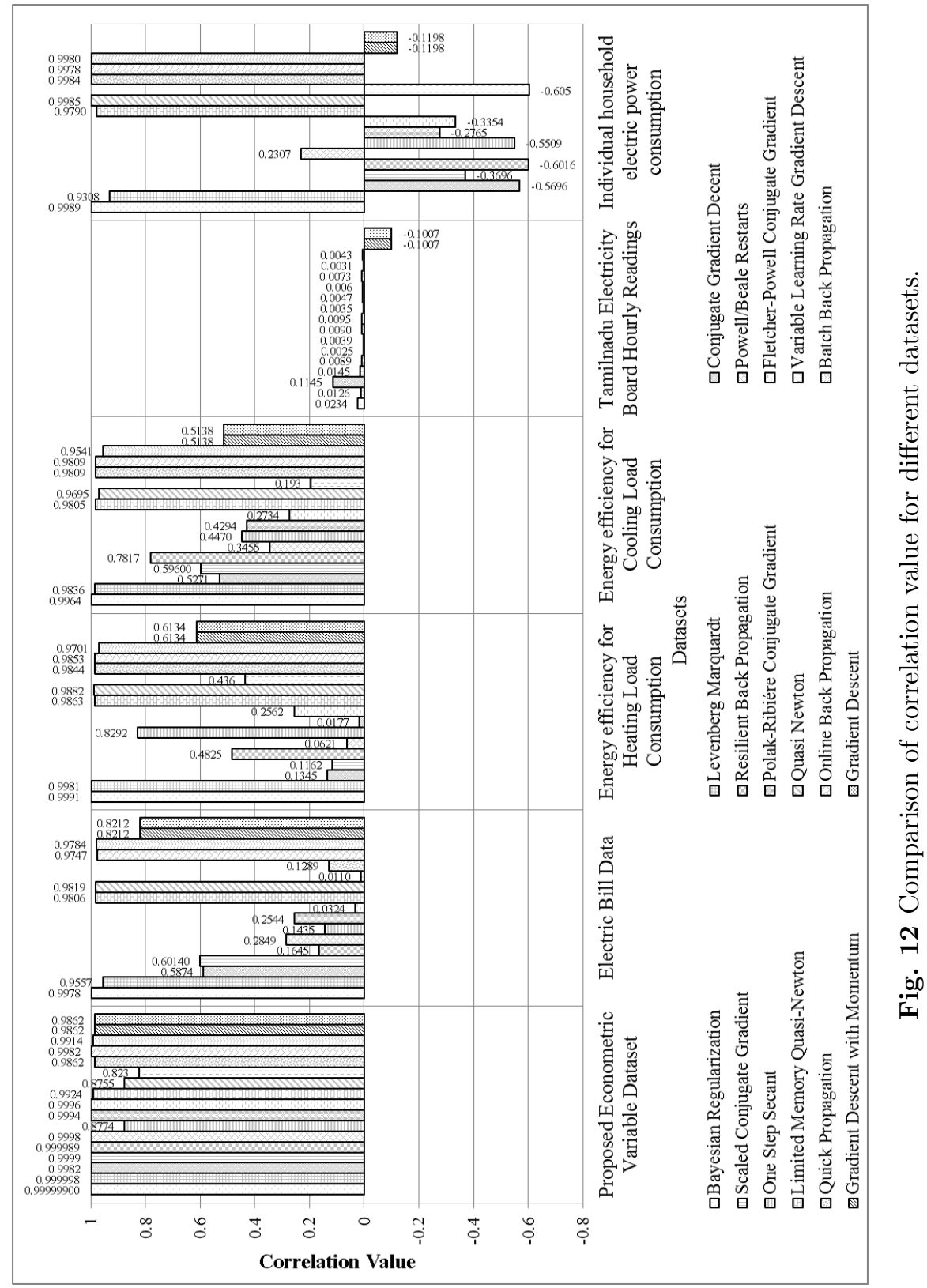


Neural Network World 1/2017, 139-178

\begin{tabular}{|c|c|c|c|c|c|}
\hline $\begin{array}{l}\text { Data } \\
\text { Source }\end{array}$ & $\begin{array}{l}\text { Name of the } \\
\text { Dataset }\end{array}$ & $\begin{array}{c}\text { No. of } \\
\text { Instance }\end{array}$ & $\begin{array}{c}\text { No. of } \\
\text { Attribute }\end{array}$ & $\begin{array}{l}\text { Response } \\
\text { Variable }\end{array}$ & $\begin{array}{l}\text { Data } \\
\text { Type }\end{array}$ \\
\hline $\begin{array}{l}\text { TNEB and } \\
\text { Economics \& } \\
\text { Statistical } \\
\text { Deparment }\end{array}$ & $\begin{array}{l}\text { Proposed Economet- } \\
\text { ric Variable Dataset }\end{array}$ & 50 & 9 & $\begin{array}{l}\text { Electricity } \\
\text { consumption }\end{array}$ & $\begin{array}{l}\text { Real \& } \\
\text { Integer }\end{array}$ \\
\hline $\begin{array}{l}\text { American } \\
\text { Statistical } \\
\text { Association }\end{array}$ & Electric Bill Data & 120 & 11 & $\begin{array}{l}\text { Calculated } \\
\text { consumption }\end{array}$ & $\begin{array}{l}\text { Real \& } \\
\text { Integer }\end{array}$ \\
\hline UCI & $\begin{array}{l}\text { Energy efficiency } \\
\text { Data for Heating } \\
\text { Load Consumption }\end{array}$ & 768 & 8 & $\begin{array}{l}\text { Heating Load } \\
\text { consumption }\end{array}$ & $\begin{array}{l}\text { Categorical } \\
\& \text {, Real }\end{array}$ \\
\hline UCI & $\begin{array}{l}\text { Energy efficiency } \\
\text { Data for Cooling } \\
\text { Load Consumption }\end{array}$ & 768 & 8 & $\begin{array}{l}\text { Cooling Load } \\
\text { consumption }\end{array}$ & $\begin{array}{l}\text { Categorical } \\
\text { \& Real }\end{array}$ \\
\hline UCI & $\begin{array}{l}\text { Tamilnadu Electric- } \\
\text { ity Board Hourly } \\
\text { Readings }\end{array}$ & 45781 & 5 & $\begin{array}{l}\text { Electricity } \\
\text { consumption }\end{array}$ & $\begin{array}{l}\text { Categorical } \\
\text { \& Real }\end{array}$ \\
\hline UCI & $\begin{array}{l}\text { Individual household } \\
\text { electric power con- } \\
\text { sumption }\end{array}$ & 2075259 & 9 & $\begin{array}{l}\text { Global active } \\
\text { power }\end{array}$ & Real \\
\hline
\end{tabular}

Tab. XIV Descriptions of UCI and American Statistical Association Datasets.

Tab. XVI shows the correlation value of the NN training algorithms for different sizes of datasets. Fig. 12 depicts the comparison of the correlation value for different datasets. From the comparative analysis, it is observed that the correlation value of the Bayesian Regularization training algorithm is higher than other training algorithms.

\section{Conclusions and future work}

The conclusion and future implementation of this survey are discussed in this section. The objective of this survey is to determine the optimal NN training algorithm for achieving effective prediction using multiple time series data. This paper has analyzed a number of NN training algorithms to identify the optimal algorithm. The accuracy parameters such as relative error and correlation coefficient of the training algorithms have been calculated. Various training algorithms are compared to find out the optimal model for Tamilnadu electricity consumption forecasting. The results show that the Bayesian regularization training algorithm with a hyperbolic tangent activation function is proved to be the optimal NN training algorithm. It effectively reduces the relative error to 0.000257 and achieves a high correlation coefficient of 0.99999993 . Due to the reduction in the relative error and improved correlation coefficient, the deviation from the actual electricity consumption is minimized. Hence, the Bayesian Regularization training algorithm is selected as the optimal training algorithm for the effective computation of electricity consump- 


\begin{tabular}{|c|c|c|c|c|c|c|}
\hline \multirow[b]{2}{*}{ 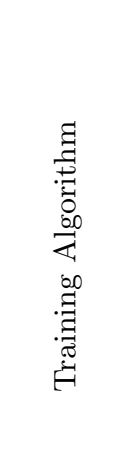 } & \multicolumn{6}{|c|}{ Dataset } \\
\hline & 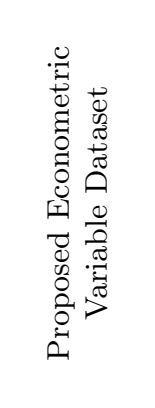 &  & 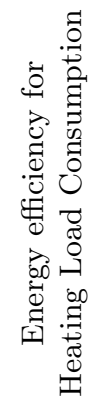 & 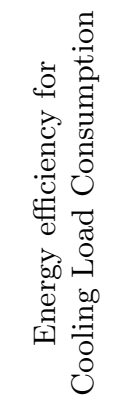 & 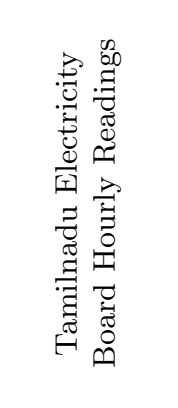 & 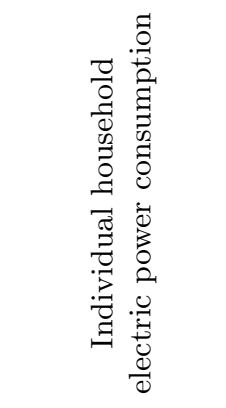 \\
\hline $\mathrm{BR}$ & 0.000257 & 1.3171 & 0.0149 & 0.0260 & 0.4364 & 0.0437 \\
\hline LM & 0.0004 & 1.8250 & 0.0211 & 0.0585 & 0.4996 & 0.1678 \\
\hline CGD & 0.03248 & 6.7212 & 0.5682 & 0.5022 & 6.9144 & 4.5233 \\
\hline $\mathrm{SCG}$ & 0.005 & 6.6921 & 0.5231 & 0.4336 & 6.5546 & 3.4272 \\
\hline $\mathrm{RBP}$ & 0.006 & 4.8824 & 1.1404 & 0.8316 & 6.5565 & 13.479 \\
\hline PBRCG & 0.008 & 6.0993 & 0.8529 & 0.3889 & 6.5716 & 0.7761 \\
\hline OSS & 0.492 & 5.4418 & 0.8848 & 0.6095 & 6.5108 & 10.248 \\
\hline PRCG & 0.017 & 6.5729 & 0.5036 & 0.9471 & 6.5376 & 4.1404 \\
\hline FPCG & 0.019 & 4.9870 & 0.6897 & 0.3353 & 6.5550 & 2.7863 \\
\hline LM-QN & 0.077 & 5.2928 & 0.0778 & 0.0600 & 6.7544 & 0.3682 \\
\hline QN & 0.491 & 5.3290 & 0.0709 & 0.0712 & 6.7527 & 0.0469 \\
\hline VLRCG & 0.687 & 3.4490 & 0.6695 & 0.4409 & 6.5655 & 7.6193 \\
\hline $\mathrm{QP}$ & 0.168 & 6.8100 & 0.0607 & 0.0609 & 6.7530 & 0.0881 \\
\hline OBP & 0.074 & 5.8410 & 0.0845 & 0.0781 & 6.8046 & 0.0751 \\
\hline $\mathrm{BBP}$ & 0.131 & 7.0351 & 0.2803 & 0.3654 & 6.7977 & 0.4654 \\
\hline GDM & 2.0638 & 5.0992 & 6.7541 & 6.3468 & 10787.4 & 11404046 \\
\hline GD & 2.0638 & 5.0992 & 6.7541 & 6.34682 & 10787.4 & 11404046 \\
\hline
\end{tabular}

Tab. XV Relative error of NN training algorithms for different sizes of datasets.

tion. It creates the computing model to find the electricity consumption using nine economical quantities. The flexibility of this method is the capacity for using the non-static parameters. The convenience of this method is the insertion of new data and this will continuously improve the estimation process. This approach combines the observed data and the unknown parameters for providing the posterior information. Finally, the economic input attributes are forecasted for the next 15 years using time series forecasting. Using these forecasted economic attributes and with the optimal Bayesian Regularization training algorithm, the electricity consumption for the next 15 years is predicted. The comparative analysis of the NN training algorithms for the proposed dataset and larger datasets obtained from the UCI repository and American Statistical Association shows that the Bayesian regularization training algorithm yields higher correlation value and lower relative error when compared to other training algorithms. The main intention of this future work is to increase the accuracy of forecasting and examining the application of neural networks for the modeling and forecasting of the electricity demand. 


\begin{tabular}{|c|c|c|c|c|c|c|}
\hline \multirow[b]{2}{*}{ 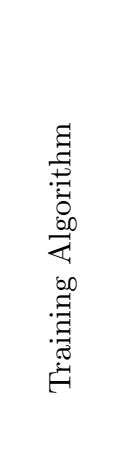 } & \multicolumn{6}{|c|}{ Dataset } \\
\hline & 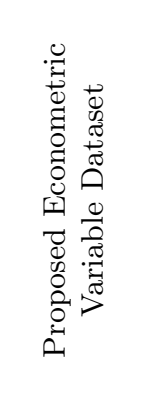 & 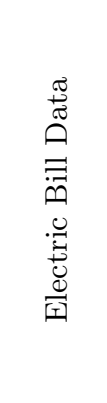 & 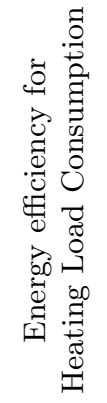 & 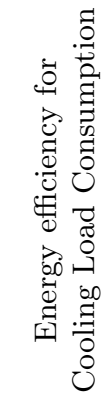 & 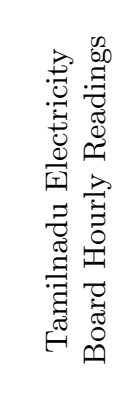 & 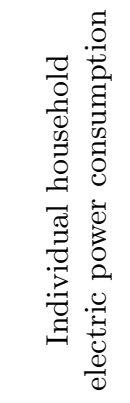 \\
\hline $\mathrm{BR}$ & 0.999999 & 0.9978 & 0.9991 & 0.9964 & 0.0234 & 0.9989 \\
\hline LM & 0.999998 & 0.9557 & 0.9981 & 0.9836 & 0.0126 & 0.9308 \\
\hline CGD & 0.9982 & 0.5874 & 0.1345 & 0.5271 & 0.1145 & -0.5696 \\
\hline $\mathrm{SCG}$ & 0.9999 & 0.6014 & 0.1162 & 0.5960 & 0.0145 & -0.3696 \\
\hline $\mathrm{RBP}$ & 0.999989 & 0.1645 & 0.4825 & 0.7817 & 0.0089 & -0.6016 \\
\hline PBRCG & 0.9998 & 0.2849 & 0.0621 & 0.3455 & 0.0025 & 0.2307 \\
\hline OSS & 0.8774 & 0.1435 & 0.8292 & 0.4470 & 0.0039 & -0.5509 \\
\hline PRCG & 0.9994 & 0.2544 & 0.0177 & 0.4294 & 0.0090 & -0.2765 \\
\hline FPCG & 0.9996 & 0.0324 & 0.2562 & 0.2734 & 0.0095 & -0.3354 \\
\hline LM-QN & 0.9924 & 0.9806 & 0.9863 & 0.9805 & 0.0035 & 0.9790 \\
\hline QN & 0.8755 & 0.9819 & 0.9882 & 0.9695 & 0.0047 & 0.9985 \\
\hline VLRCG & 0.8228 & 0.0106 & 0.4356 & 0.1933 & 0.0062 & -0.6048 \\
\hline $\mathrm{QP}$ & 0.9862 & 0.1289 & 0.9844 & 0.9809 & 0.0073 & 0.9984 \\
\hline $\mathrm{OBP}$ & 0.9982 & 0.9747 & 0.9853 & 0.9809 & 0.0031 & 0.9978 \\
\hline $\mathrm{BBP}$ & 0.9914 & 0.9784 & 0.9701 & 0.9541 & 0.0043 & 0.9980 \\
\hline GDM & 0.9862 & 0.8212 & 0.6134 & 0.5138 & -0.1007 & -0.1198 \\
\hline GD & 0.9862 & 0.8212 & 0.6134 & 0.5138 & -0.1007 & -0.1198 \\
\hline
\end{tabular}

Tab. XVI Correlation value of NN training algorithms for different sizes of datasets.

\section{Acknowledgement}

We would like to thank the reviewers for their insightful comments on the paper, as these comments led us to an improvement of the work. We would also like to thank the Tamil Nadu Electricity Board and the Economics and Statistics Department, Tamilnadu, India for the provision of information and support, without which this research paper would not have been possible.

\section{References}

[1] ALYUDA NEUROINTELLIGENCE [Software]. Available from: http://www.alyuda.com/.

[2] AN N., ZHAO W., WANG J., SHANG D., ZHAO E. Using multi-output feedforward neural network with empirical mode decomposition based signal filtering for electricity demand forecasting. Energy. 2013, 49, pp. 279-288, doi: 10.1016/j.energy.2012.10.035. 
Usha T.M., Appavu alias Balamurugan S.: Computational modeling of electricity...

[3] ANGELIKI X. UCI Machine Learning Repository Energy efficiency Data Set 2012. Available from: http://archive.ics.uci.edu/ml/datasets/Energy\$+\$efficiency.

[4] BUHARI M., ADAMU S.S. Short-term load forecasting using artificial neural network. Proceedings of the IMECS. 2012.

[5] CHANG P-C., FAN C-Y., LIN J-J. Monthly electricity demand forecasting based on a weighted evolving fuzzy neural network approach. International Journal of Electrical Power 83 Energy Systems. 2011, 33(1), pp. 17-27, doi: 10.1016/j.ijepes.2010.08.008.

[6] CHEN T. A collaborative fuzzy-neural approach for long-term load forecasting in Taiwan. Computers \& Industrial Engineering. 2012, 63(3), pp. 663-670, doi: 10.1016/j.cie.2011. 06.003.

[7] Chitsaz H., SHAKER H., ZAREIPOUR H., WOOD D., AMJADY N. Short-term electricity load forecasting of buildings in microgrids. Energy and Buildings. 2015, 99, pp. 50-60, doi: $10.1016 / j$. enbuild.2015.04.011.

[8] DILAVER Z., HUNT L.C. Modelling and forecasting Turkish residential electricity demand. Energy Policy. 2011, 39(6), pp. 3117-3127, doi: 10.1016/j .enpol.2011.02.059.

[9] DILAVER Z., HUNT L.C. Turkish aggregate electricity demand: an outlook to 2020. Energy. 2011, 36(11), pp. 6686-6696, doi: 10.1016/j.energy.2011.07.043.

[10] DORDONNAT V., KOOPMAN S.J., OOMS M. Dynamic factors in periodic time-varying regressions with an application to hourly electricity load modelling. Computational Statistics E6 Data Analysis. 2012, 56(11), pp. 3134-3152, doi: 10.1016/j.csda.2011.04.002.

[11] DUDEK G., ed. Forecasting time series with multiple seasonal cycles using neural networks with local learning. Artificial Intelligence and Soft Computing. 2013, pp. 52-63, doi: 10. 1007/978-3-642-38658-9_5.

[12] ERWAY J.B., MARCIA R.F. On efficiently computing the eigenvalues of limited-memory quasi-newton matrices. SIAM Journal on Matrix Analysis and Applications. 2015, 36(3), pp. 1338-1359, doi: 10.1137/140997737.

[13] FAN S., HYNDMAN R.J. Short-term load forecasting based on a semi-parametric additive model. IEEE Transactions on Power Systems. 2012, 27(1), pp. 134-141, doi: 10.1109/TPWRS . 2011.2162082

[14] FRINCU M., CHELMIS C., NOOR M.U., PRASANNA V., eds. Accurate and efficient selection of the best consumption prediction method in smart grids. Proceedings of the IEEE in ternational conference on Big Data, 2014, pp. 721-729, doi: 10.1109/BigData.2014.7004296.

[15] HÉBRAIL G., BÉRARD A. Individual household electric power consumption Data Set. UCI Machine Learning Repository, 2012. Available from: https://archive.ics.uci.edu/ $\mathrm{ml} /$ datasets/Individual\$+\$household $\$+\$$ electric $\$+\$$ power $\$+\$$ consumption.

[16] HALL M. Time Series Analysis and Forecasting with Weka-Pentaho Data Mining [Software] [Accessed: 10-Aug-2013]. Available from: http://wiki.pentaho.com/display/DATAMINING/ Time $\$+\$$ Series $\$+\$$ Analysis $\$+\$$ and $\$+\$$ Forecasting $\$+\$$ with $\$+\$$ Weka.

[17] HASSAN S., KHOSRAVI A., JAAFAR J. Examining performance of aggregation algorithms for neural network-based electricity demand forecasting. International Journal of Electrical Power 85 Energy Systems. 2015, 64, pp. 1098-105, doi: 10.1016/j.ijepes.2014.08.025.

[18] HERNANDEZ L., BALADRON C., AGUiAR J.M., CARRO B., SANCHEZESGUEVILLAS A.J., LLORET J. A survey on electric power demand forecasting: Future trends in smart grids, microgrids and smart buildings. IEEE Communications Surveys 83 Tutorials. 2014, 16(3), pp. 1460-1495, doi: 10.1109/SURV.2014.032014.00094.

[19] HERNANDEZ L., BALADRON C., AGUiAR J.M., CARRO B., SANCHEZESGUEVILLAS A.J., LLORET J. A multi-agent system architecture for smart grid management and forecasting of energy demand in virtual power plants. IEEE Communications Magazine. 2013, 51(1), pp. 106-113, doi: 10.1109/MC0M. 2013.6400446.

[20] JARAMILLO-MORÁN M.A., GONZÁLEZ-ROMERA E., CARMONA-FERNÁNDEZ D. Monthly electric demand forecasting with neural filters. International Journal of Electrical Power 63 Energy Systems. 2013, 49, pp. 253-263, doi: 10.1109/MCOM.2013.6400446. 


\section{Neural Network World 1/2017, 139-178}

[21] KALYANI K. Tamilnadu Electricity Board Hourly Readings Data Set Available from: https://archive.ics.uci.edu/ml/datasets/Tamilnadu\$+\$Electricity\$+\$Board\$+ \$Hourly\$+\$Readings.

[22] KAYTEZ F., TAPLAMACIOGLU M.C., CAM E., HARDALAC F. Forecasting electricity consumption: A comparison of regression analysis, neural networks and least squares support vector machines. International Journal of Electrical Power 83 Energy Systems. 2015, 67, pp. 431-438, doi: 10.1016/j.ijepes.2014.12.036.

[23] KELO S., DUDUL S. A wavelet Elman neural network for short-term electrical load prediction under the influence of temperature. International Journal of Electrical Power 8 Energy Systems. 2012, 43(1), pp. 1063-1071, doi: 10.1016/j.ijepes.2012.06.009.

[24] KHEIRKHAH A., AZADEH A., SABERI M., AZARON A., SHAKOURI H. Improved estimation of electricity demand function by using of artificial neural network, principal component analysis and data envelopment analysis. Computers $\mathcal{E}$ Industrial Engineering. 2013, 64(1), pp. 425-441, doi: 10.1016/j.cie.2012.09.017.

[25] KIRAN M.S., ÖZCEYLAN E., GÜNDÜZ M., PAKSOY T. A novel hybrid approach based on particle swarm optimization and ant colony algorithm to forecast energy demand of Turkey. Energy conversion and management. 2012, 53(1), pp. 75-83, doi: 10.1016/j.enconman. 2011. 08.004 .

[26] LIU Z., LI W., SUN W. A novel method of short-term load forecasting based on multiwavelet transform and multiple neural networks. Neural Computing and Applications. 2013, 22(2), pp. 271-277, doi: 10.1007/s00521-011-0715-2.

[27] LLANOS J., SÁEZ D., PALMA-BEHNKE R., JIMÉNEZ-ESTÉVEZ G., eds. Load profile generator and load forecasting for a renewable based microgrid using self organizing maps and neural networks. Proceedings of International Joint Conference on Neural Networks. 2012, pp. 1-8, doi: 10.1109/IJCNN. 2012.6252648.

[28] MARINESCU A., HARRIS C., DUSPARIC I., CLARKE S., CAHILL V., eds. Residential electrical demand forecasting in very small scale: An evaluation of forecasting methods. Proceedings of 2nd International Workshop on Software Engineering Challenges for the Smart Grid (SE4SG), 2013, pp. 25-32, doi: 10.1109/SE4SG.2013.6596108.

[29] MATLAB Release 2013b [Software]. The MathWorks, Inc., Natick, Massachusetts, United States. https://in.mathworks.com/products/new_products/release2013b.html.

[30] MCLAREN C., MCLAREN B. Electric Bill Data. Available from: http://www.amstat.org/ publications/jse/datasets/electricbill.txt.

[31] MELLIT A., PAVAN A.M., LUGHI V. Short-term forecasting of power production in a largescale photovoltaic plant. Solar Energy. 2014, 105, pp. 401-413, doi: 10.1016/j.solener. 2014.03.018.

[32] MOTAMEDI A., ZAREIPOUR H., ROSEHART W.D. Electricity price and demand forecasting in smart grids. IEEE Transactions on Smart Grid. 2012, 3(2), pp. 664-674 doi: 10.1109/TSG.2011.2171046.

[33] MURUGADOSS R., RAMAKRISHNAN M., editors. Universal approximation using probabilistic neural networks with sigmoid activation functions. Proceedings of International Conference on Advances in Engineering and Technology Research (ICAETR), 2014, pp. 1-4, doi: 10.1109/ICAETR . 2014.7012920.

[34] NAYAK S, CHOUDHURY B, LENKA SK, eds. Gradient Descent with Momentum Based Backpropagation Neural Network for Selection of Industrial Robot. Proceedings of First International Conference on Information and Communication Technology for Intelligent Systems. 2016, 1, pp. 487-496, doi: 10.1007/978-3-319-30933-0_49.

[35] NIU D-X., SHI H-F., WU D.D. Short-term load forecasting using bayesian neural networks learned by Hybrid Monte Carlo algorithm. Applied Soft Computing. 2012, 12(6), pp. 18221827. doi: $10.1016 / j$.asoc.2011.07.001.

[36] RAHPEYMAII F., KIMIAEI M., BAGHERI A. A limited memory quasi-Newton trustregion method for box constrained optimization. Journal of Computational and Applied Mathematics. 2016, 303, pp. 105-118, doi: 10.1016/j.cam.2016.02.026. 
Usha T.M., Appavu alias Balamurugan S.: Computational modeling of electricity...

[37] RAZA M.Q., KHOSRAVI A. A review on artificial intelligence based load demand forecasting techniques for smart grid and buildings. Renewable and Sustainable Energy Reviews. 2015, 50, pp. 1352-1372, doi: 10.1016/j.rser.2015.04.065.

[38] SANDHU P.S., CHHABRA S. A comparative analysis of Conjugate Gradient Algorithms \& PSO Based Neural Network approaches for reusability evaluation of procedure based software systems. Chiang Mai j Sci. 2011, 38(2), pp. 123-35, Available from: http://www. thaiscience.info/journals/Article/CMJS/10905403.pdf.

[39] SHAO Z., GAO F., YANG S-L., YU B-G. A new semiparametric and EEMD based framework for mid-term electricity demand forecasting in China: Hidden characteristic extraction and probability density prediction. Renewable and Sustainable Energy Reviews. 2015, 52, pp. 876-89, doi: 10.1016/j.rser.2015.07.159.

[40] SHEN W., BABUSHKIN V., AUNG Z., WOON W.L., editors. An ensemble model for day-ahead electricity demand time series forecasting. Proceedings of the fourth international conference on Future energy systems, ACM, 2013, pp. 51-62, doi: 10.1145/2487166. 2487173.

[41] SIGAUKE C., CHIKOBVU D. Prediction of daily peak electricity demand in South Africa using volatility forecasting models. Energy Economics. 2011, 33(5), pp. 882-888, doi: 10. 1016/j.eneco.2011.02.013.

[42] SOUSA J., NEVES L., JORGE H. Assessing the relevance of load profiling information in electrical load forecasting based on neural network models. International Journal of Electrical Power 8 Energy Systems. 2012, 40(1), pp. 85-93. doi: 10.1016/j.ijepes.2012.02.008.

[43] SUGANTHI L., SAMUEL A.A. Energy models for demand forecasting - A review. Renewable and sustainable energy reviews. 2012, 16(2), pp. 1223-1240. doi: 10.1016/j.rser.2011.08. 014.

[44] VILAR J.M., CAO R., ANEIROS G. Forecasting next-day electricity demand and price using nonparametric functional methods. International Journal of Electrical Power \& Energy Systems. 2012, 39(1), pp. 48-55, doi: 10.1016/j.ijepes.2012.01.004.

[45] WANG C-H., GROZEV G., SEO S. Decomposition and statistical analysis for regional electricity demand forecasting. Energy. 2012, 41(1), pp. 313-25, doi: 10.1016/j .energy. 2012. 03.011.

[46] WANG J., CHI D., WU J., LU H-Y. Chaotic time series method combined with particle swarm optimization and trend adjustment for electricity demand forecasting. Expert Systems with Applications. 2011, 38(7), pp. 8419-8429, doi: 10.1016/j.eswa.2011.01.037.

[47] WANG J., MA X., WU J., DONG Y. Optimization models based on GM $(1,1)$ and seasonal fluctuation for electricity demand forecasting. International Journal of Electrical Power \& Energy Systems. 2012, 43(1), pp. 109-117, doi: 10.1016/j.ijepes.2012.04.027.

[48] WANG L., ZENG Y., CHEN T. Back propagation neural network with adaptive differential evolution algorithm for time series forecasting. Expert Systems with Applications. 2015, 42(2), pp. 855-863, doi: 10.1016/j.eswa.2014.08.018.

[49] WANG Y., WANG J., ZHAO G., DONG Y. Application of residual modification approach in seasonal ARIMA for electricity demand forecasting: a case study of China. Energy Policy. 2012, 48, pp. 284-294, doi: 10.1016/j.enpol.2012.05.026.

[50] WEBBERLEY A., GAO DW. Study of artificial neural network based short term load forecasting. IEEE Power and Energy Society General Meeting (PES). 2013, pp. 1-4, doi: 10. 1109/PESMG. 2013.6673036.

[51] YOKOYAMA J., CHIANG H-D. Short Term Load Forecasting improved by ensemble and its variations. IEEE Power and Energy Society General Meeting. 2012, pp. 1-6, doi: 10. 1109/PESGM. 2012.6345222.

[52] YU S-W., ZHU K-J. A hybrid procedure for energy demand forecasting in China. Energy. 2012, 37(1), pp. 396-404, doi: 10.1016/j.energy.2011.11.015.

[53] ZAHEDI G., AZIZI S., BAHADORI A., ELKAMEL A., ALWI SRW. Electricity demand estimation using an adaptive neuro-fuzzy network: a case study from the Ontario provinceCanada. Energy. 2013, 49, pp. 323-328, doi: 10.1016/j.energy.2012.10.019. 


\section{Neural Network World 1/2017, 139-178}

[54] ZHANG H., WU W., YAO M. Boundedness and convergence of batch back-propagation algorithm with penalty for feedforward neural networks. Neurocomputing. 2012, 89, pp. 141146. doi: 10.1016/j. neucom.2012.02.029.

[55] ZHU S., WANG J., ZHAO W., WANG J. A seasonal hybrid procedure for electricity demand forecasting in China. Applied Energy. 2011, 88(11), pp. 3807-3815, doi: 10.1016/j . apenergy . 2011.05 .005 